\title{
Repression of Death Receptor-Mediated Apoptosis of Hepatocytes by Hepatitis B Virus e Antigen
}

\author{
Wei Liu, ${ }^{* \dagger}$ Teng-Fei Guo, ${ }^{*}$ Zhen-Tang Jing, ${ }^{\ddagger}$ and Qiao-Yun Tong ${ }^{* \dagger}$
}

From the Institute of Digestive Disease, * China Three Gorges University, Yichang; the Department of Gastroenterology, ${ }^{\dagger}$ Yichang Central People’s Hospital, Yichang; and the Key Laboratory of Tumor Microbiology, ${ }^{\ddagger}$ Fujian Medical University, Fuzhou, China

\author{
Accepted for publication \\ July 8, 2019. \\ Address correspondence to Wei \\ Liu, Ph.D., or Qiao-Yun Tong, \\ M.D., Institute of Digestive \\ Disease, China Three Gorges \\ University, 8 Daxue Rd., \\ Yichang 443000, China. E- \\ mail: liuwei@ctgu.edu.cn or \\ ycxhnk@ctgu.edu.cn.
}

\begin{abstract}
Hepatitis $B$ virus ( $\mathrm{HBV})$ e antigen $(\mathrm{HBeAg})$ is associated with viral persistence and pathogenesis. Resistance of HBV-infected hepatocytes to apoptosis is seen as one of the primary promotors for HBV chronicity and malignancy. Fas receptor/ligand (Fas/FasL) and the tumor necrosis factor (TNF)-related apoptosis-inducing ligand (TRAIL) system plays a key role in hepatic death during HBV infection. We found that $\mathrm{HBeAg}$ mediates resistance of hepatocytes to FasL or TRAIL-induced apoptosis. Introduction of $\mathrm{HBeAg}$ into human hepatocytes rendered resistance to FasL or TRAIL cytotoxicity in a p53-dependent manner. HBeAg further inhibited the expression of p53, total Fas, membrane-bound Fas, TNF receptor superfamily member 10a, and TNF receptor superfamily member 10b at both mRNA and protein levels. In contrast, $\mathrm{HBeAg}$ enhanced the expression of soluble forms of Fas through facilitation of Fas alternative mRNA splicing. In a mouse model, expression of $\mathrm{HBeAg}$ in mice injected with recombinant adenovirus-associated virus 8 inhibited agonistic anti-Fas antibody-induced hepatic apoptosis. Xenograft tumorigenicity assay also found that $\mathrm{HBeAg}$-induced carcinogenesis was resistant to the proapoptotic effect of TRAIL and chemotherapeutic drugs. These results indicate that HBeAg may prevent hepatocytes from FasL and TRAIL-induced apoptosis by regulating the expression of the proapoptotic and antiapoptotic forms of death receptors, which may contribute to the survival and persistence of infected hepatocytes during HBV infection. (Am J Pathol 2019, 189: 2181-2195; https://doi.org/10.1016/j.ajpath.2019.07.014)
\end{abstract}

Hepatitis B virus (HBV) infection remains a major health problem worldwide because approximately 240 million individuals are chronically infected with HBV. ${ }^{1}$ Meanwhile, the detailed mechanisms underlying chronic and acute HBV infection and deep pathophysiologic processes have not been well defined. It is well known that HBV infection may regulate the apoptotic signal to accelerate viral proliferation and hepatocellular carcinoma progression. ${ }^{2-4}$ Hepatic apoptosis during HBV infection is mostly mediated by death signaling from members of the tumor necrosis factor (TNF) protein family, including TNF- $\alpha$, Fas ligand (FasL), and TNF-related apoptosis-inducing ligand (TRAIL). ${ }^{5}$ Fas, a typical glycoprotein, is abundantly distributed in the liver cell membrane and triggers apoptosis signals to the hepatocytes when Fas ligand (FasL) or agonistic anti-Fas antibody binds with it. ${ }^{6}$ FasL forcefully induces massive hepatic apoptosis in healthy liver or most types of liver disease. Primary human and mice hepatocytes are sensitive to apoptosis induced by the agonistic anti-Fas antibody and active FasL. ${ }^{7}$ Fas is also considered a soluble molecule ( $\mathrm{sFas}$ ) beside its membrane-associated form (mFas), ${ }^{8}$ indicating a deeper layer of complexity in regulation of apoptosis. sFas, arising from alternatively spliced Fas mRNA, leads to proteins with deletion or disruption of the single membrane-spanning domain. ${ }^{8}$ Serum sFas is increased in patients with chronic and acute hepatitis B- or HBV-related hepatocellular carcinoma. 9,10

Supported by National Natural Science Foundation of China grant 31600134 (W.L.); and Open Research Fund of Key Laboratory of Tumor Microbiology, Fujian Medical University grant FMUTM-201704 (W.L.).

W.L. and T-F.G. contributed equally to this work.

Disclosure: None declared. 
The Fas/FasL apoptosis signal is strictly regulated at both receptor and intracellular apoptotic signaling events. Previous studies suggest that Fas transcription is activated by tumor suppressor gene $p 53$ in hepatocytes, and the cross talk between the Fas signaling and p53 in controlling apoptosis is of clinical importance. ${ }^{11-13}$ The key role of p53 in HBVdependent control of apoptotic signal is not clear, but it has been reported that the regulation of apoptosis by HBV core protein $(\mathrm{HBc})$ may be $\mathrm{p} 53$ dependent and independent. ${ }^{2,14,15}$ Similar to FasL, TRAIL also activates the p53-dependent extrinsic pathway by binding to the death receptors, such as TNF receptor superfamily member $10 \mathrm{a}$ (DR4) and TNF receptor superfamily member $10 \mathrm{~b}$ (DR5) at the cell surface. $^{16,17}$

The multifunction of the hepatitis B e antigen (HBeAg) remains unknown because it is not essential for viral replication, assembly, and infection. ${ }^{18}$ The clinical data reveal that secreted $\mathrm{HBeAg}$ can play an immunoregulatory role in HBV natural infection. However, intracellular $\mathrm{HBeAg}$ acts as a target for the specific immune response. The dual roles of the HBeAg and its ability to activate or tolerize $\mathrm{T}$ cells reveal the complexity of the interactions between the host and the $\mathrm{HBeAg}$ during viral infection. ${ }^{19,20}$ However, HBeAg and its precursors may function as a significant enhancer of hepatocellular carcinoma through many mechanisms, including repressing p53 activity through interacting with NUMB. ${ }^{21}$ The original intention of this research is to investigate whether $\mathrm{HBeAg}$ is involved in controlling the Fas and TRAIL apoptosis pathway. We found that $\mathrm{HBeAg}$ inhibits the FasL- and TRAIL-induced apoptosis of hepatocytes in vitro and in vivo by regulating the expression of proapoptotic and antiapoptotic form of death receptors.

\section{Materials and Methods}

\section{Ethics Statement}

Cryopreserved primary human hepatocytes (PHHs) were purchased from BioreclamationIVT (Brussels, Belgium), which obtains and distributes consented human material from a network of institutional review board-approved collection sites under adherence to effective ethical and regulatory guidelines.

\section{Cell Lines and Cell Culture}

The human hepatoma cell lines HepG2 (wild-type p53), Huh-7 (mutant p53), Hep3B (deficient p53), and primary mouse hepatocytes (PMHs) were cultured as previously described. $^{2,22}$ PHHs were thawed according to the manufacturer's instructions and cultured in William's Medium E (Sigma-Aldrich, St. Louis, MO) supplemented with $10 \%$ fetal bovine serum, $2 \mathrm{mmol} / \mathrm{L} \mathrm{L}$-glutamine, and $100 \mathrm{U} / \mathrm{mL}$ of penicillin with $100 \mathrm{mg} / \mathrm{mL}$ of streptomycin.

\section{Plasmid Constructs}

pcDNA3.1-HBeAg, pcDNA3.1-precore, pcDNA3.1-p22, and pcDNA3.1-p53 were kindly provided by Dr. De-yin Guo (School of Basic Medical Sciences, Wuhan University, Wuhan, China). ${ }^{21}$ The promoter-driving firefly luciferase containing Fas (pGL4.10-Fas), DR4 (pGL4.10-DR4), and DR5 (pGL4.10-DR5) was constructed by ligation of the PCR-generated respective minimal promoter into the luciferase reporter plasmid pGL4.10 Vector (Promega, Madison, WI) as described previously. ${ }^{12,16,17}$

The schematic diagram of the strategy used for pRep-HBV and pRep-Sal construction has been described previously. ${ }^{15}$ The p56 plasmid, which is a pUC18 backbone that contains the full-length HBV DNA genome from strain 56 that has a high replication efficiency ( $3215 \mathrm{bp}$, genotype B, adw subtype; https://www.ncbi.nlm.nih.gov/nuccore; accession number AF100309), was digested first with XbaI and RsrII. A 1.3-kb DNA fragment called $\mathrm{C}$ was recovered, which corresponds to the 249- to 1573-nt region of the HBV genome. The p56 plasmid was then digested with SapI to release the free $56 \mathrm{HBV}$ DNA, followed by self-ligation. The resulting circular DNA was digested with BamHI and $\mathrm{XbaI}$, and a 2.0-kb fragment called B was recovered. Fragment B corresponds to the 1402- to 249-nt region of the HBV genome that contains the basic core promoter with Enhancer I. Next, a 0.4-kb fragment called D, which corresponds to the 1573- to 2000-nt region of the HBV genome, was amplified by PCR and digested with RsrII and SalI. The primers used included pC: $5^{\prime}$ CATTTCCATGGCTGCTAGGC- $3^{\prime}$ and pD: 5' ACGCGTCGACGAGATCTCGAATAGAAGGAAAG-3' . Finally, to exclude the possible influence of gene transcription upstream of the HBV DNA, a transcription blocker fragment was generated by PCR amplification, using the pSEAP-Basic plasmid (Clontech, Palo Alto, CA) as a template. The primers used were TBf: 5'ACGCGTCGACAATAAAATATCTTTATTTTC-3' and TBr: 5'-CGCGGATCCAGAGAAATGTTCTGGCACC-3', and the $0.1-\mathrm{kb}$ amplified fragment called $\mathrm{A}$ was digested with SalI and BamHI. Fragments A to D were ligated headto-tail into the pREP10 vector (Invitrogen, Carlsbad, CA), which had the expression cassette, including the Rous sarcoma virus long terminal repeat and polyadenylation signal removed by SalI digestion. The recombinant plasmid, called pREP-HBV, was confirmed by restriction enzyme digest and DNA sequence analyses. The control plasmid, named pREP-SalI, was constructed by removing the expression cassette, including the Rous sarcoma virus long terminal repeat and polyadenylation signal from pREP10 by Sall digestion, followed by self-ligation.

The pRep-HBV-HBeAg(-) and pRep-HBV- HBeAg\&$\mathrm{HBc} \& \mathrm{HBx}(-)$ triple mutation plasmids were generated by site-directed mutagenesis as described previously. ${ }^{23}$ The pRep-HBV-HBeAg(-) contains the nonsense mutation site 28th aa of HBeAg. The pRep-HBV- HBeAg\&HBc\&HBx(-) 
contains both the nonsense mutation site 38th aa of $\mathrm{HBcAg}$ and 8th aa of HBx.

\section{Construction of Stable HBeAg-Expressing Hepatoma Cell Lines}

The hepatoma cells were transfected with $\mathrm{pHBeAg}$ or the empty control plasmid and then selected in the presence of $400 \mu \mathrm{g} / \mathrm{mL}$ of hygromycin for 4 weeks. The hygromycinresistant clones were expanded together into cell lines and screened for the extent of $\mathrm{HBeAg}$ protein expression by Western blot analysis.

\section{Production of HBeAg-Expressing Recombinant Adenoviruses}

The detailed procedures of construction and generation of the recombinant adenoviruses are described previously. ${ }^{24}$

\section{Generation of HBeAg-Expressing Recombinant Lentivirus}

Thirty-percent confluent $293 \mathrm{~T}$ cell monolayers in $10-\mathrm{cm}$ culture dishes were cotransfected with pCDH-HBeAgFLAG and the packaging vectors of pMDL, p-VSV-G, and pREV (Invitrogen) and cultured for 48 hours. The culture medium was collected and clarified by low-speed centrifugation. The supernatant after filtration through 0.45$\mu \mathrm{m}$ filters was added into the culture of PHH cells grown in 6-cm culture dishes. The expression of $\mathrm{HBeAg}$ was confirmed by Western blot analysis.

\section{AAV Injection}

The adeno-associated virus (AAV) -8 expression system was used to achieve overexpression of wild-type $\mathrm{HBeAg}$ in liver. High-titer AAV-8 particles were produced and supplied by Obio Technology Corp Ltd. (Shanghai, China). A total of $2 \times 10^{11} \mathrm{vg}$ of AAV-8 in $100 \mu \mathrm{L}$ of phosphate-buffered saline (PBS) was intravenously injected into age-matched (6 to 8 weeks old) C57BL/6 mice weighing 16 to $18 \mathrm{~g}$. Mice were subsequently treated for 3 weeks.

\section{Isolation of PMHs}

PMHs were isolated from C57BL/6 male mice by a two-step collagenase perfusion technique. ${ }^{22}$ Briefly, live hepatic parenchymal cells were separated by $35 \%$ Percoll. After seeding for 4 to 6 hours, cells were refreshed with medium and cultured overnight.

\section{Animal Experiments}

All work performed with animals was in accordance with and approved by the Institutional Animal Care and Use
Committee at Fujian Medical University. The Institutional Animal Care and Use Committee protocol number for the study is M00186. Male, age-matched (6 to 8 weeks old) C57BL/6 mice (Shanghai Institutes for Biological Sciences, Chinese Academy of Sciences, Shanghai, China) weighing 16 to $18 \mathrm{~g}$ were maintained in ventilated cages under a 12hour light/dark cycle. Mice at 3 weeks after injection with $\mathrm{HBeAg}$-expressing or empty control AAV-8 were treated intraperitoneally with the agonistic anti-Fas Jo2 antibody (554255; BD Pharmingen, San Diego, CA) diluted in 100 $\mu \mathrm{L}$ of PBS at $0.2 \mu \mathrm{g} / \mathrm{g}$. The same dosage of mouse IgG (catalog number 555740; BD Biosciences, San Jose, CA) was used as a control for Jo2. Liver and blood samples were taken at 12 hours after injection of the antibody. Serum levels of alanine transaminase were determined using a standard clinical automatic analyzer (Hitachi 7020, Hitachi, Kyoto, Japan). Immediately after the blood samples were taken retro-orbitally, mice were sacrificed by cervical dislocation. The liver was excised, sectioned, and fixed overnight at $4^{\circ} \mathrm{C}$ in $10 \%$ formalin solution. The sections were then dehydrated, paraffin embedded, and cut at 3-mm thickness and stained with hematoxylin and eosin for histologic examination.

\section{Tumor Xenograft Experiments and TRAIL Treatment}

Tumor xenograft experiments in nude mice were performed as previously described. ${ }^{25}$ One week later, mice ( 5 per group) were randomly assigned to one of four treatment groups: PBS, TRAIL $10 \mathrm{mg} / \mathrm{kg}$ per day i.p., doxorubicin (Adriamycin; Sigma-Aldrich) $0.1 \mathrm{mg} / \mathrm{kg}$ per day i.p., or TRAIL $10 \mathrm{mg} / \mathrm{kg}$ per day i.p. and doxorubicin $0.1 \mathrm{mg} / \mathrm{kg}$ per day i.p. Mice were treated for an additional 3 weeks. The induction of apoptosis in formalin-fixed, paraffinembedded hepatoma xenografts was measured by the terminal deoxynucleotidyl transferase-mediated dUTP nickend labeling (TUNEL) assay (Promega).

\section{Plasmid Transfection and RNA Interference}

Transient transfections with various plasmids were performed as previously described. ${ }^{2}$ siRNAs against the P53 gene p53 siRNA (sc-29435, Santa Cruz Biotechnology, Dallas, TX) and corresponding control siRNA (sc-37007, Santa Cruz Biotechnology) were transfected into HepG2 cells in six-well plates using the X-tremeGENE siRNA Transfection Reagent (Roche Applied Science, Penzberg, Germany) according to the manufacturer's instructions. Gene silencing effect was confirmed by Western blot analysis and RT-PCR at 48 hours after transfection.

\section{Western Blot Analysis}

Western blot analysis was described previously. ${ }^{2,26}$ The specific antibodies used in this study included anti-FLAG (catalog number 14793, 1:1000 dilution, Cell Signaling 
Technology, Beverly, MA), anti- $\beta$-tubulin (catalog number 2128, 1:1000 dilution, Cell Signaling Technology), anti-p53 (K0181-3, 1:1000 dilution, MBL, Nagoya, Japan), antimFas (catalog number 4233, 1:1000 dilution, Cell Signaling Technology), anti-DR4 (catalog number 42533, 1:1000 dilution, Cell Signaling Technology), anti-DR5 (catalog number 8074, 1:1000 dilution, Cell Signaling Technology), anti-Fas (ab82419, 1:1000 dilution, Abcam, Cambridge, UK), anti-HBc (sc-23947, 1:500 dilution, Santa Cruz Biotechnology), and anti-HBx (sc-57760, 1:500 dilution, Santa Cruz Biotechnology).

\section{Treatment of Cells with Chemicals and Antibodies}

In HepG2 cells or PHHs, Fas receptor stimulation was performed with $10 \mathrm{ng} / \mathrm{mL}$ of super-hFasL (ALX-522-020, Enzo Life Sciences Inc., Farmingdale, NY). DR4/DR5 receptor stimulation was performed with $1 \mu \mathrm{g} / \mathrm{mL}$ of active recombinant human soluble TRAIL (catalog number 310-04, PeproTech, Rocky Hill, NJ). In PMHs, Fas receptor stimulation was performed with the agonistic monoclonal antibody anti-Fas Jo2 (catalog number 554255, BD Pharmingen) alone at $2 \mu \mathrm{g} / \mathrm{mL}$. To enhance FasL-induced apoptosis, cells were pretreated with the $60 \mu \mathrm{g} / \mathrm{mL}$ of the p53 inducer bleomycin (Sigma-Aldrich) or $0.2 \mu \mathrm{g} / \mathrm{mL}$ of doxorubicin (SigmaAldrich). To neutralize TRAIL-induced apoptosis, cells were pretreated with $10 \mu \mathrm{g} / \mathrm{mL}$ of DR4 (HS101, 10 P's BVBA, Breda, the Netherlands) and/or DR5 blocking antibody (HS201, 10 P's BVBA, Breda, the Netherlands).

\section{HBeAg Quantitative Analysis}

Levels of cell medium and serum $\mathrm{HBeAg}$ was tested quantitatively by Architect assay (Abbott Laboratories, Chicago, IL). The Architect assay is a two-step immunoassay according to the method of chemiluminescent microparticles. Briefly, samples were mixed with paramagnetic beads presenting anti-HBeAg antibodies. After a washing step, a conjugate and reactant were added and a light signal was emitted, which was proportional to $\mathrm{HBeAg}$ concentration within a linear-wide range. Standardized calibration of the Architect assay was performed using the World Health Organization international standard for $\mathrm{HBeAg}$ (subtype adw2, genotype A). The Architect $\mathrm{HBeAg}$ assay is calibrated to give results in international units per milliliter.

\section{CCK-8 Assay}

Cell proliferation and viability were measured using a CCK8 assay as previously described. ${ }^{27}$

\section{TUNEL Assay}

Liver tissues were dissected and fixed in $4 \%$ paraformaldehyde overnight, dehydrated, embedded in paraffin, and then subjected to a TUNEL assay as previously reported. ${ }^{27}$

\section{Annexin V Binding Assay}

Cells were treated with proapoptotic chemicals and/or antibodies. Apoptosis was detected using an fluorescein isothiocyanate annexin $\mathrm{V}$ apoptosis detection kit (BD Pharmingen) according to the manufacturer's instructions and analyzed by flow cytometry (FACSVerse; BD Biosciences) using FACSuite software version 1.0 (BD Biosciences).

\section{Quantitative Real-Time PCR Analysis}

Quantitative real-time PCR analysis was described previously. 2,28

\section{Semiquantitative RT-PCR Analysis of mFas and sFas}

Transcribed cDNA was used as a template for PCR amplification. The paired primers $\mathrm{P} 1$ and $\mathrm{P} 2$ were used for total Fas amplification and $\mathrm{P} 3$ and $\mathrm{P} 5$ for $\mathrm{mFas} / \mathrm{sFas}$ amplification; primer sequences were reported previously. ${ }^{2}$ PCR products were analyzed on a $2.5 \%$ agarose gel by electrophoresis and ethidium bromide staining. A digital image of the gel was obtained using a SynGene apparatus and the SynGeneGeneSnap software version 4.00.00 (SynGene, San Diego, CA). Individual band intensities were quantitated using the densitometric software Quantity One version 4.6 (Bio-Rad, Hercules, CA). sFas or mFas mRNA level was expressed as a ratio of $\mathrm{sFas}$ or $\mathrm{mFas}$ PCR product signal to that of glyceraldehyde-3-phosphate dehydrogenase.

\section{ELISA for sFas, TNF- $\alpha$, and IL- 6}

sFas in cell culture supernates was detected using a human sFas enzyme-linked immunosorbent assay (ELISA) kit (R\&D Systems, Minneapolis, MN) according to the manufacturer's instructions. Cytokine concentrations in the mice serum were examined by ELISA (ADI-900-047 of Peprotech for TNF- $\alpha$ and KMC0061 of Invitrogen for IL-6). The absorbance of each well was measured at $450 \mathrm{~nm}$ using a microplate reader (Bio-Rad). The concentrations of the cytokines were calibrated from a dose-response curve based on reference standards.

\section{Fas Splicing Assay}

The procedures for Fas splicing assay were followed exactly as previously described.

\section{Caspase Enzymatic Activity Assay}

Activities of caspase 3/7 were measured by using the ApoONETM Homogeneous Caspase-Glo 3/7 assay kit, respectively (G8091, Promega), according to the manufacturer's instructions. 

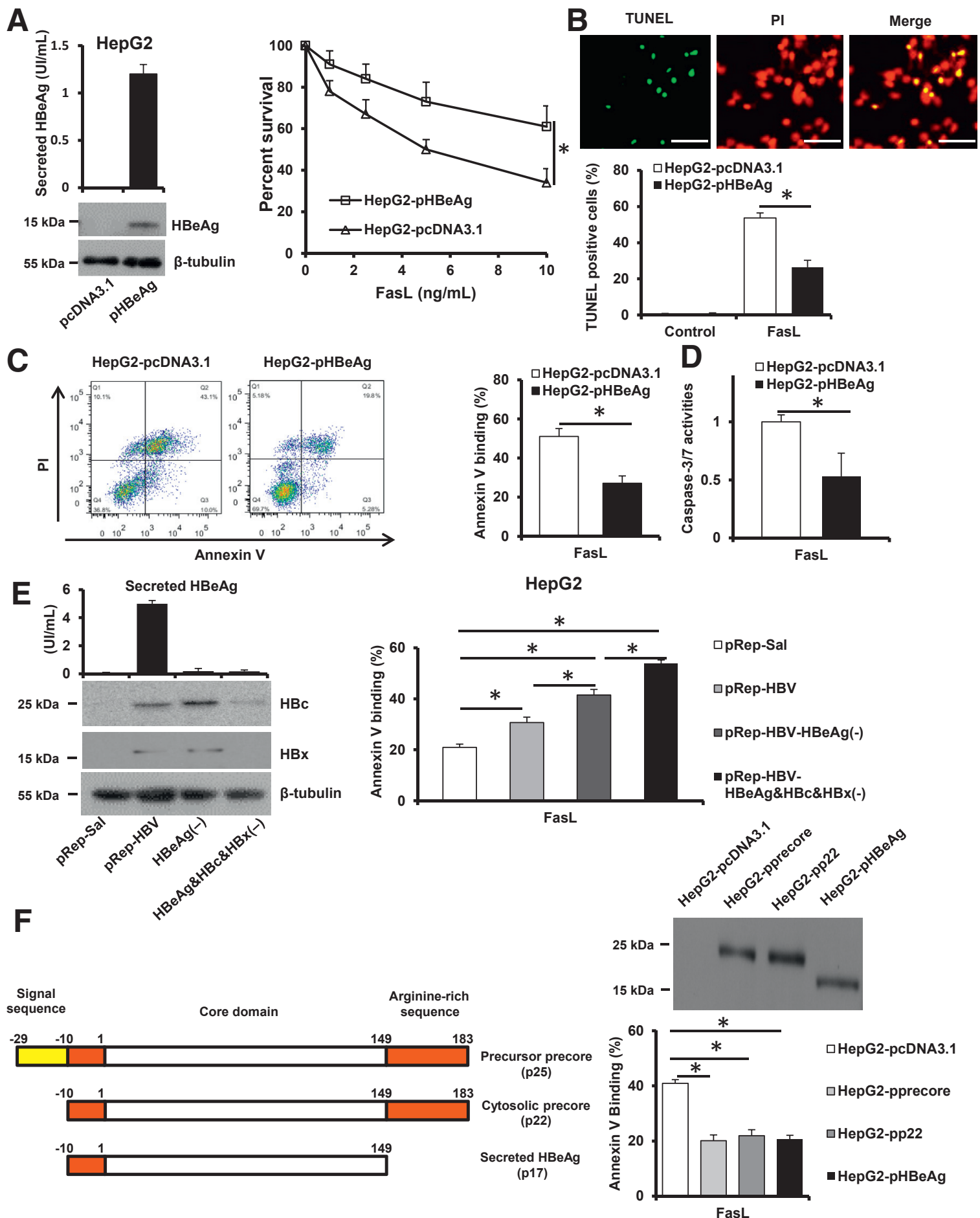

Figure 1 Hepatitis B virus (HBV) e antigen ( $\mathrm{HBeAg}$ ) transfection decreases the sensitivity of hepatoma cells to Fas ligand (FasL)-induced apoptosis. A: Intracellular HBeAg expression in HepG2 cells verified by Western blot analysis using the FLAG tag antibody and secreted HBeAg by Architect assay. The Architect HBeAg assay is calibrated to give results in international units per milliliter. Cell viability determined by CCK-8 assay 24 hours after HepG2-pcDNA or HepG2-pHBeAg cells were treated with increasing concentrations of FasL. B: Terminal deoxynucleotidyl transferase-mediated dUTP nick-end labeling (TUNEL) staining performed on HepG2-pcDNA or HepG2-pHBeAg cells treated with FasL for 24 hours. Quantification of apoptotic cells stained with TUNEL and expressed as percentage of the number of TUNEL-positive cells to the total number of cells counted. C: Quantification of apoptotic cell fractions by annexin V/propidium iodide (PI) staining. Cells received the same treatments as indicated in panel $\mathbf{B}$ and were subjected to flow cytometric analysis. D: Measurements of caspase-3/ 7 enzymatic activity expressed as the fold change relative to that in control cells. E: Expression of HBeAg, HBc, and HBx in HepG2-pRep HBV, HepG2-pRep HBV HBeAg(-), HepG2-pRep HBV HBeAg(-), and HBc\&HBx(-) cells was assessed by Western blot analysis. Flow cytometric analysis on the fraction of apoptotic cells 8 hours after the indicated cells were treated with FasL. F: $\mathrm{HBeAg}$ and its precursors received the same treatments as indicated in panel $\mathbf{E}$ and were subjected to flow cytometric analysis. Data are expressed as means \pm SD. $n=3$. ${ }^{*} P<0.05\left[t\right.$-test $(\mathbf{A}$ and $\mathbf{D})$ and $\chi^{2}$ test $(\mathbf{B}, \mathbf{C}, \mathbf{E}$, and $\left.\mathbf{F})\right]$. Scale bars $=100 \mu \mathrm{m}$. 


\section{Dual-Luciferase Reporter Assay}

HepG2-pcDNA3.1 or HepG2-pHBeAg cells were transfected with $0.2 \mu \mathrm{g}$ of pGL4.10-promoter reporter plasmids and $0.2 \mu \mathrm{g}$ of the Renilla luciferase expression vector pRLTK. The cells were harvested 48 hours after the transfection. A total of $20 \mu \mathrm{g}$ of cell lysate was used for the detection of intracellular luciferase activity by the Dual-Luciferase Reporter Assay System (Promega) following the manufacturers' recommendations. The firefly luciferase activity was normalized against the Renilla reniformis luciferase activity of the co-transfected pRL-TK to control for variations in transfection efficiency. The relative luciferase units were obtained by comparison with the pGL4.10-promoter reporters in HepG2-pcDNA3.1, which was set to 1. Luminescence was measured on a luminometer (Orion II Microplate Luminometer, Berthold Detection Systems, Pforzheim, Germany).

\section{Statistical Analysis}

The $\chi^{2}$ test was used to analyze differences between the apoptosis rates. The statistical significance in the differences between mRNA and protein levels was analyzed by analysis of variance. The least significant difference method was used to further post hoc analysis. The differences between two groups were analyzed by using a $t$-test. $P<0.05$ was considered statistically significant. All analyses were performed by IBM SPSS software version 19.0 (IBM Corp, Armonk, NY). Data are presented as means \pm SD determined from a minimum of three independent experiments each performed with triplicate cultures.

\section{Results}

HBeAg Decreases the Sensitivity of Hepatoma Cells to FasL-Induced Apoptosis

To explore the role of $\mathrm{HBeAg}$ in regulation of apoptosis, HepG2 (wild-type p53) sublines stably transfected with control vector or $\mathrm{HBeAg-expressing} \mathrm{pcDNA3.1-HBeAg}$ were generated and their sensitivity verified to the active proapoptotic FasL. The successful expression of intracellular or secreted $\mathrm{HBeAg}$ was confirmed by Western blot analysis and Architect assay (Figure 1A). The CCK-8 assay was used to explore whether $\mathrm{HBeAg}$ expression could modulate cellular sensitivity to FasL. The FasL concentration-survival curves reveal that HepG2 cells expressing $\mathrm{HBeAg}$ (HepG2-pHBeAg) were less sensitive to the cytotoxic effect of FasL compared with control (Figure 1A). To explore whether the increased viability of HepG2-pHBeAg cells was due to decreased apoptosis, the frequency of apoptotic cells was tested by the TUNEL assay. A marginal but significant decrease in the rate of apoptosis after $10-\mathrm{ng} / \mathrm{mL}$ FasL treatment was detected in the HepG2-pHBeAg population compared with control (Figure 1B). Furthermore, the decreased apoptosis of HepG2 cells augmented by $\mathrm{HBeAg}$ was also determined by annexin $\mathrm{V}$ binding or caspase-3/7 activities (Figure 1, C and D). An opposite result was defined with HepG2 cells transfected with 1.2-U lengths of the HBV genome (pRep-HBV), revealing the
A
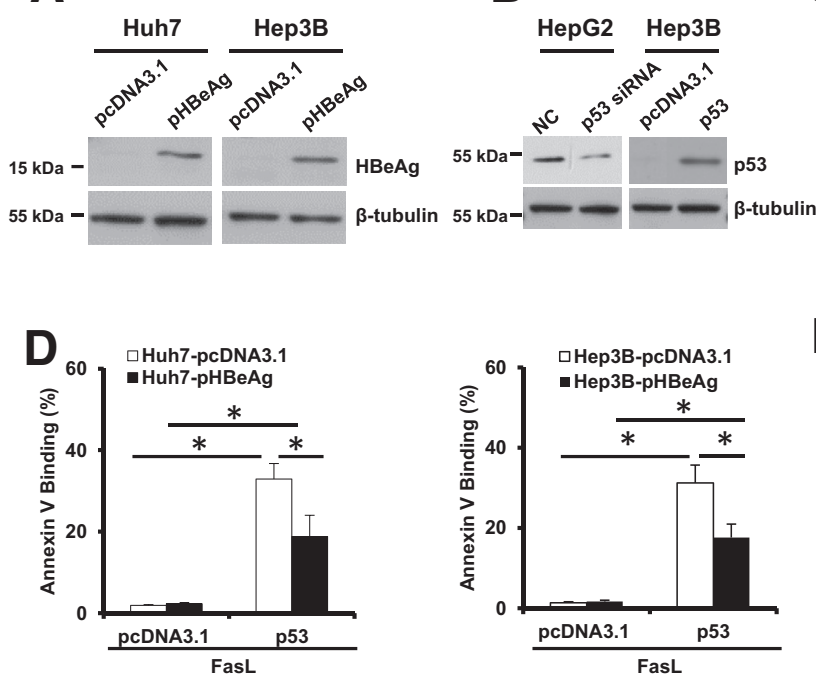

B

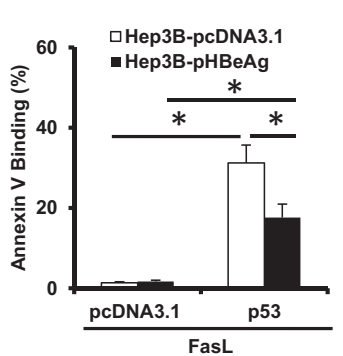

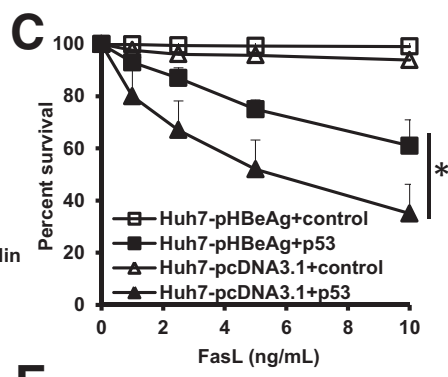

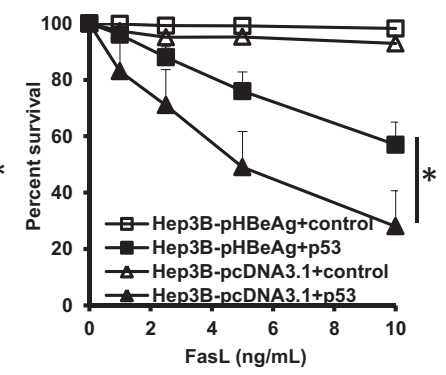

E

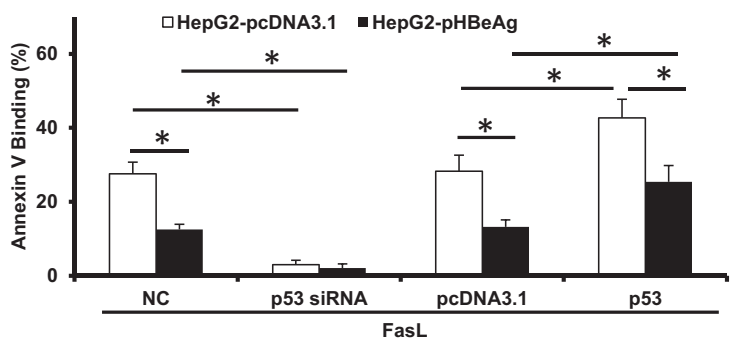

Figure 2 Regulation of hepatitis B virus (HBV) e antigen (HBeAg) on Fas-induced apoptosis depends on wild-type p53 status. A and B: The expression of HBeAg in Huh7 and Hep3B cells stably transfected with pHBeAg or the control vector was confirmed. Western blot analysis for HepG2 or Hep3B cells transiently transfected with p53 siRNA or $p 53$ gene. C: Cell viability determined by CCK-8 assay 24 hours after Huh7-pcDNA3.1 and Huh7-pHBeAg or Hep3BpcDNA3.1 and Hep3B-pHBeAg cells treated with increasing concentrations of Fas ligand (FasL). D: Annexin V staining performed on Huh7-pcDNA3.1 and Huh7-pHBeAg or Hep3B-pcDNA3.1 and Hep3B-pHBeAg cells treated with FasL for 8 hours. E: Annexin V staining performed on HepG2-pcDNA3.1 or HepG2pHBeAg cells treated with FasL for 8 hours with transfection with p53 siRNA or $p 53$ gene. Data are expressed as means \pm SD. $n=3 .{ }^{*} P<0.05[t$-test (C) or $\chi^{2}$ test $(\mathbf{D}$ and $\left.\mathbf{E})\right]$. NC, negative control. 

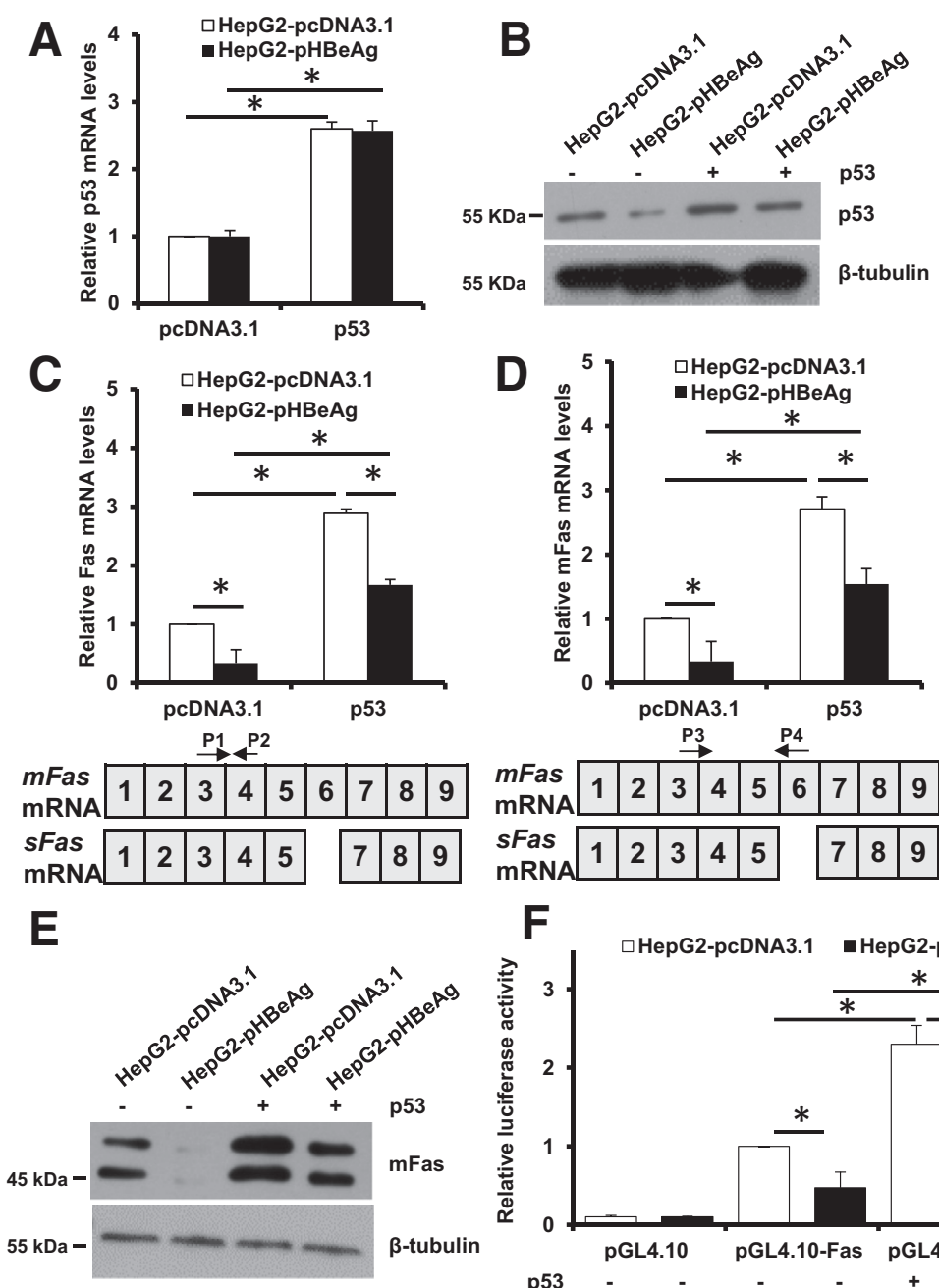

Figure 3 Regulation of hepatitis B virus (HBV) e antigen ( $\mathrm{HBeAg}$ ) on $\mathrm{p} 53$ and Fas transcription and expression. A: Quantitative real-time PCR analysis of $\mathrm{p} 53$ mRNA levels in HepG2-pcDNA3.1 and HepG2-pHBeAg cells on $\mathrm{p} 53$ overexpression. B: The effect of HBeAg transfection on p53 protein levels is shown by Western blot. C: Quantitative real-time PCR analysis of total Fas mRNA levels in HepG2-pcDNA3.1 and HepG2-pHBeAg cells on p53 overexpression. The primer $\mathrm{P} 1$ is located in exon $3 / 4$ of the Fas gene and the primer P2 located in exon 4 of Fas gene. D: Quantitative real-time PCR analysis of membrane-associated Fas (mFas) mRNA levels in HepG2pcDNA3.1 and HepG2-pHBeAg cells. The primer P3 is located in exon $3 / 4$ of the Fas gene, and the primer $\mathrm{P} 4$ is located in exon 6 of the Fas gene. E: The effect of HBeAg transfection on $\mathrm{mFas}$ protein levels on $\mathrm{p} 53$ overexpression is shown by Western blot. F: Transcriptional regulation of Fas by HBeAg. HepG2-pcDNA3.1 or HepG2-pHBeAg cells were co-transfected with pGL4.10-Fas that contained the Fas promoter sequence and the Renilla luciferase expression vector pRL-TK on p53 overexpression. The level of promoter activity was evaluated 48 hours after transfection by measuring the luciferase activity normalized for variations in transfection efficiency and expressed as the fold change relative to the untreated HepG2pcDNA3.1 cells. Data are expressed as means \pm SD (A $-\mathbf{F}) . n=3 .{ }^{*} P<0.05$ (analysis of variance). enhanced sensitivity to Fas-induced apoptosis (Figure 1E). Interestingly, transfection of the HBeAg mutant pRep-HBV$\mathrm{HBeAg}(-)$ into HepG2 further strengthened Fas-induced apoptosis compared with cells transfected with pRep-HBV (Figure 1E). Both $\mathrm{HBc}$ and $\mathrm{HBx}$ inhibit Fas-mediated apoptosis. $^{2,28}$ Expectedly, transfection of $\mathrm{HBeAg}, \mathrm{HBc}$, and HBx triple mutant pRep-HBV-HBeAg\&HBc\&HBx(-) into HepG2 greatly increased Fas-induced apoptosis compared with cells transfected with pRep-HBV and pRep-Sall (Figure 1E). Lastly, HBeAg and its precursors (precore, p22) had the equal inhibitory effects of Fas apoptotic signal (Figure 1F). The data reveal that $\mathrm{HBeAg}$ may limit the sensitivity of HepG2 cells to Fas-mediated apoptosis and likely to function as an antagonist of Fas/FasL-induced hepatic apoptosis.

\section{HBeAg Control of FasL-Induced Apoptosis Depends on Wild-Type p53 Status}

The Fas receptor could be directly transactivated by p53 in hepatoma cells. ${ }^{11,29}$ Whether reduction of Fas-mediated apoptosis by HBeAg was through a p53-dependent manner was tested using Huh7 and Hep3B, which represents p53 mutant ${ }^{30}$ and p53 null ${ }^{31}$ status, respectively. The two human hepatoma cell lines were stably transfected with pcDNA3.1-HBeAg, and $\mathrm{HBeAg}$ expression was determined in Huh7-pHBeAg and Hep3B-pHBeAg cells (Figure 2A). Meanwhile, the effect of p53 siRNA or overexpression was verified in HepG2 and Hep3B cells (Figure 2B). Interestingly, only in the presence of wild-type p53 did FasL treatment generate effective and differential cytotoxicity to Huh7-pHBeAg or Hep3B-pHBeAg cells (Figure 2, C and D). To further confirm the key role of p53 in Fas apoptotic signal, p53 wild-type HepG2-pcDNA3.1 and HepG2pHBeAg cells were transfected with p53 siRNA or p53 gene followed by FasL treatment then tested for annexin $\mathrm{V}$ binding assay. As expected, transfection with p53 siRNA fully abrogated FasL-induced apoptosis regardless of HBeAg expression, whereas p53 overexpression powerfully enhanced the apoptosis rate, with the effect being greater in control than the HepG2-pHBeAg cells (Figure 2E). Totally, the data strongly illustrate that inhibition of Fas-mediated 

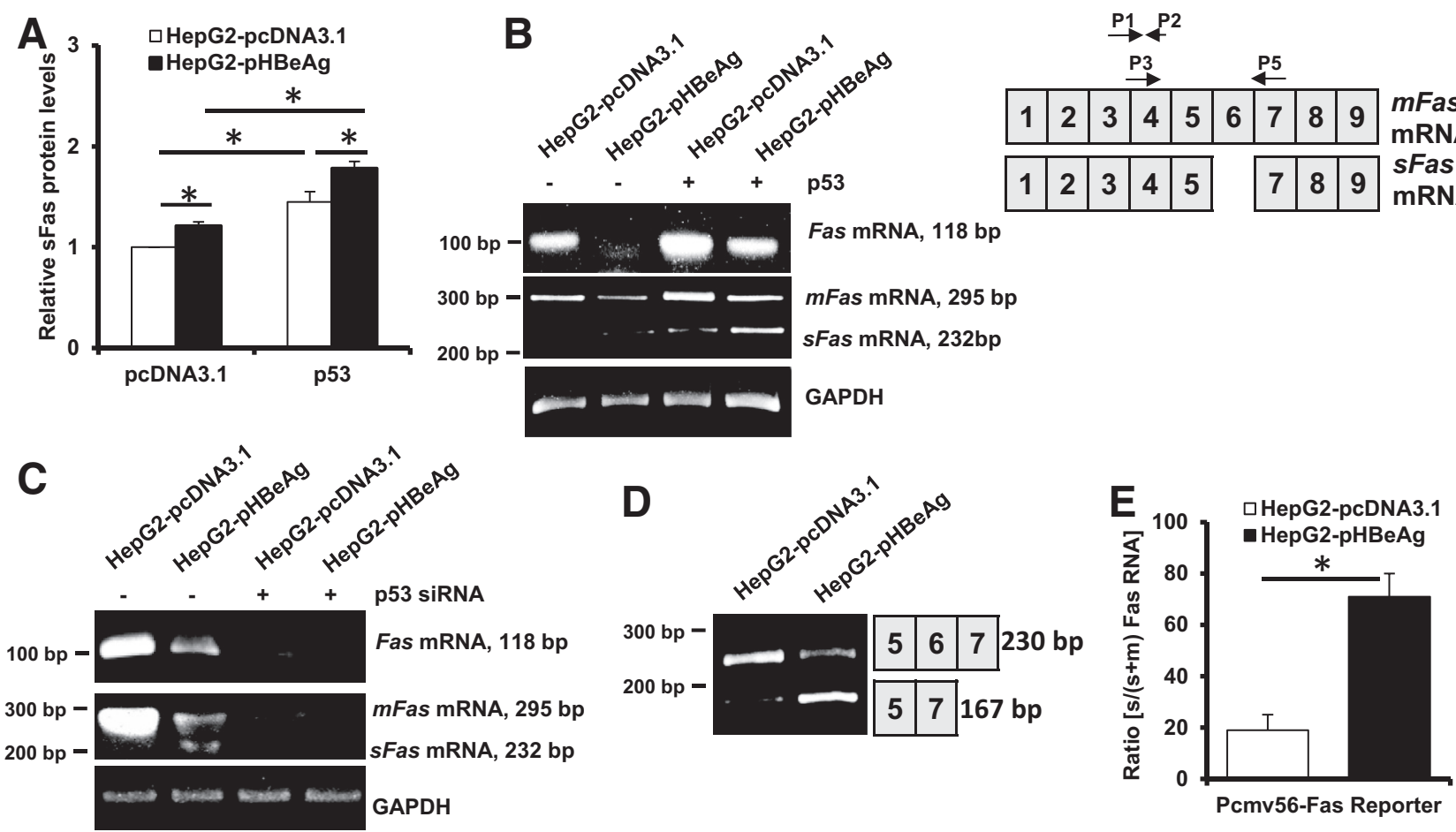

Figure 4 Hepatitis B virus (HBV) e antigen ( $\mathrm{HBeAg})(\mathrm{HBeAg})$ enhances soluble Fas (sFas) transcription and expression. A: Expression of sFas in culture medium of HepG2-pcDNA3.1 and HepG2-pHBeAg cells measured by enzyme-linked immunosorbent assay on p53 expression. B and C: Semiquantitative RTPCR analysis of total Fas, membrane-associated Fas (mFas), and sFas mRNA levels in HepG2-pcDNA3.1 and HepG2-pHBeAg cells on p53 overexpression and knockdown. The PCR product using paired primers P1 and P2 represents total Fas, whereas the PCR products of paired primers P3 and P5 (located at exon 7 ) represent $\mathrm{mFas}$ and sFas varied by size. D: Representative agarose gel image showing the accumulation of alternatively spliced transcripts in HepG2pcDNA3.1 and HepG2-pHBeAg cells transfected with pCMV56-Fas vector that contained human Fas genomic sequences from exons 5 to 7 . The products were analyzed on agarose gels (expected size: $230 \mathrm{bp}$ for exon 6 inclusion and $167 \mathrm{bp}$ for exon 6 skipping). E: The ratio of exons $5+7$ to exons $5+6+7$ amplification products, equivalent to ratio of sFas to ( $\mathrm{sFas}+\mathrm{mFas}$ ) RNA, determined densitometrically on the band intensity from three independent experiments in the pCMV56-Fas transfected HepG2-pcDNA3.1 and HepG2-pHBeAg cells. Data are expressed as means \pm SD. $n=3$. ${ }^{*} P<0.05$ [analysis of variance $(\mathbf{A}-\mathbf{C})$ and $t$-test $(\mathbf{E})]$.

hepatic apoptosis by $\mathrm{HBeAg}$ depends on wild-type p53 status.

\section{HBeAg Inhibits p53 and Fas Expression}

Considering that $\mathrm{HBeAg}$ inhibited Fas apoptotic signal, which depends on p53 expression, and that HBeAg could down-regulate p53 expression, ${ }^{21}$ the relative expression of p53 and Fas in control and HepG2-HBeAg cells on p53 overexpression was determined by quantitative RT-PCR and Western blot analysis. Transfection of HepG2pcDNA3.1 and HepG2-HBeAg cells with p53 enhanced p53 expression at both mRNA (Figure 3A) and protein levels (Figure 3B), representing the effectiveness of the treatment. Meanwhile, the augmentation was less pronounced in HepG2-pHBeAg cells compared with control only at protein levels. Similar data were calculated with total Fas mRNA levels (Figure 3C) and mFas at both mRNA (Figure 3D) and protein levels (Figure 3E). Then, cells were transfected with Fas promoter-driven luciferase reporter construct pGL4.10-Fas to evaluate changes in possible $\mathrm{HBeAg}$-regulated promoter inactivation. HepG2-pHBeAg cells illustrated an obvious decrease of luciferase reporter gene activity relative to control (Figure 3F). The results suggest that $\mathrm{HBeAg}$ may down-regulate p53-dependent Fas expression at the transcriptional level.

\section{HBeAg Enhances sFas Transcription and Expression}

sFas arising from alternatively spliced Fas mRNA is a soluble form of Fas lacking exon 6 and has been considered as an antagonist of Fas apoptotic signal. ${ }^{32}$ The effects of $\mathrm{HBeAg}$ on sFas expression were subsequently evaluated in the context of $\mathrm{p} 53$ overexpression. In the absence of p53, the level of sFas in the culture medium of HepG2-pHBeAg cells as measured by ELISA was higher than control (Figure 4A). Transfection of cells with p53 further enhanced sFas expression, which was verified by semiquantitative PCR analysis. Although sFas mRNA levels were increased in HepG2-pHBeAg cells compared with control cells (Figure 4B) with or without p53 overexpression, knockdown of p53 significantly blocked the $\mathrm{HBeAg}$-induced $\mathrm{sFas}$ mRNA levels (Figure 4C). The Fas splicing assay was also performed in the cells transfected with Fas splicing reporter construct pCMV56 containing the human Fas receptor sequences spanning from exon 5 to exon 7 , kindly provided 

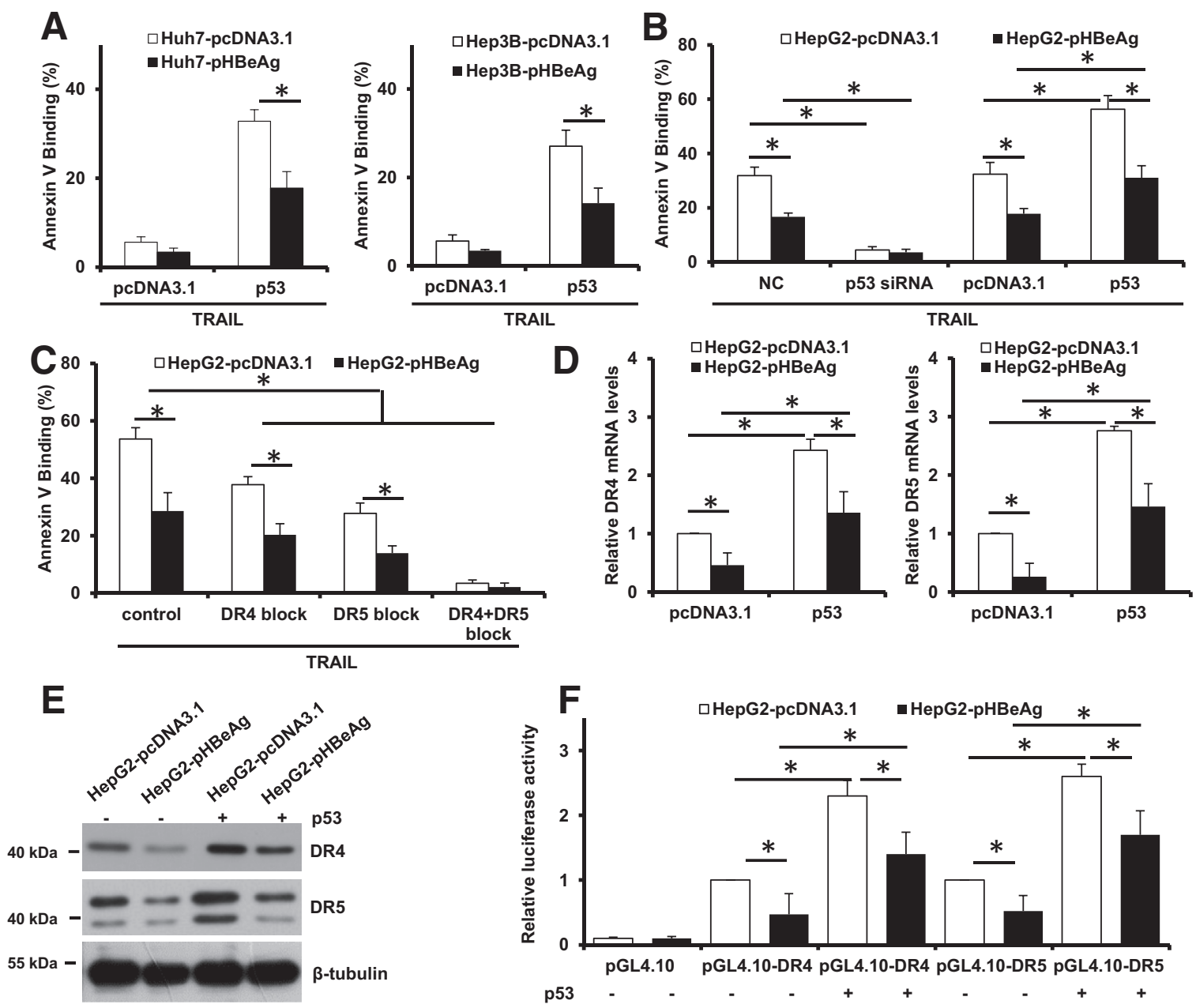

Figure 5 Inhibition of tumor necrosis factor (TNF)-related apoptosis-inducing ligand TR(TRAIL)-mediated apoptosis by hepatitis B virus (HBV) e antigen (HBeAg). A: Annexin V staining performed on Huh7-pcDNA3.1 and Huh7-pHBeAg or Hep3B-pcDNA3.1 and Hep3B-pHBeAg cells treated with TRAIL for 12 hours. B: Annexin V staining performed on of HepG2-pcDNA3.1 or HepG2-pHBeAg cells treated with TRAIL for 12 hours with transfection with p53 siRNA or p53 gene. C: Annexin V staining performed on of HepG2-pcDNA3.1 or HepG2-pHBeAg cells treated with TRAIL for 12 hours with pretreatment with TNF receptor superfamily member 10a (DR4) and/or TNF receptor superfamily member 10b (DR5) blocking antibody. D: Quantitative real-time PCR analysis of total DR4 or DR5 mRNA levels in HepG2-pcDNA3.1 and HepG2-pHBeAg cells on p53 overexpression. E: Representative Western blot showing the effect of HBeAg transfection on DR4 or DR5 protein levels on p53 overexpression. F: Transcriptional regulation of DR4 or DR5 by HBeAg. HepG2-pcDNA3.1 or HepG2-pHBeAg cells were co-transfected with pGL4.10-DR4 or DR5 and the Renilla luciferase expression vector pRL-TK on p53 overexpression. The level of promoter activity was evaluated. Data are expressed as means \pm SD. $n=3 .{ }^{*} P<0.05\left[\chi^{2}\right.$ test $(\mathbf{A}-\mathbf{C})$ and analysis of variance (D-F)]. NC, negative control.

by Dr. J. Valca'rcel. These data revealed that relative mRNA levels of Fas exon 5/7 (representative of sFas) to Fas exons 5 to 7 in HepG2-HBeAg were obviously increased as compared with control (Figure 4, D and E). The results indicate that $\mathrm{HBeAg}$ promotes $\mathrm{sFas}$ transcription and expression via increasing transcripts of an alternatively spliced variant that specifically encodes the soluble form of the receptors.

\section{Inhibition of TRAIL-Mediated Apoptosis by HBeAg}

TRAIL is a cytokine that is produced and secreted by most normal tissue cells and causes p53-dependent apoptosis primarily in tumor or virus-infected cells by binding to certain death receptors such as DR4 and DR5. ${ }^{16,17}$
Therefore, the inhibitory effect of $\mathrm{HBeAg}$ on p53-dependent TRAIL-mediated apoptosis was examined. Interestingly, TRAIL treatment produced effective and differential cytotoxicity to hepatoma cells expressing $\mathrm{HBeAg}$ only in the presence of $\mathrm{p} 53$ (Figure 5, A and B). To further ascertain the central role of DR4 and DR5 receptors in TRAILmediated apoptosis, p53 wild-type HepG2-pcDNA3.1 and HepG2-pHBeAg cells were pretreated with DR4 and/or DR5 blocking antibodies followed by exposure to TRAIL then assayed for annexin V binding assay. As expected, only pretreatment with both DR4- and DR5-blocking antibodies fully abrogated TRAIL-induced apoptotic cell death (Figure 5C), and there was no obvious difference in the apoptotic rate between HepG2-pHBeAg and control cells, which indicates combined effect of the two receptors in 

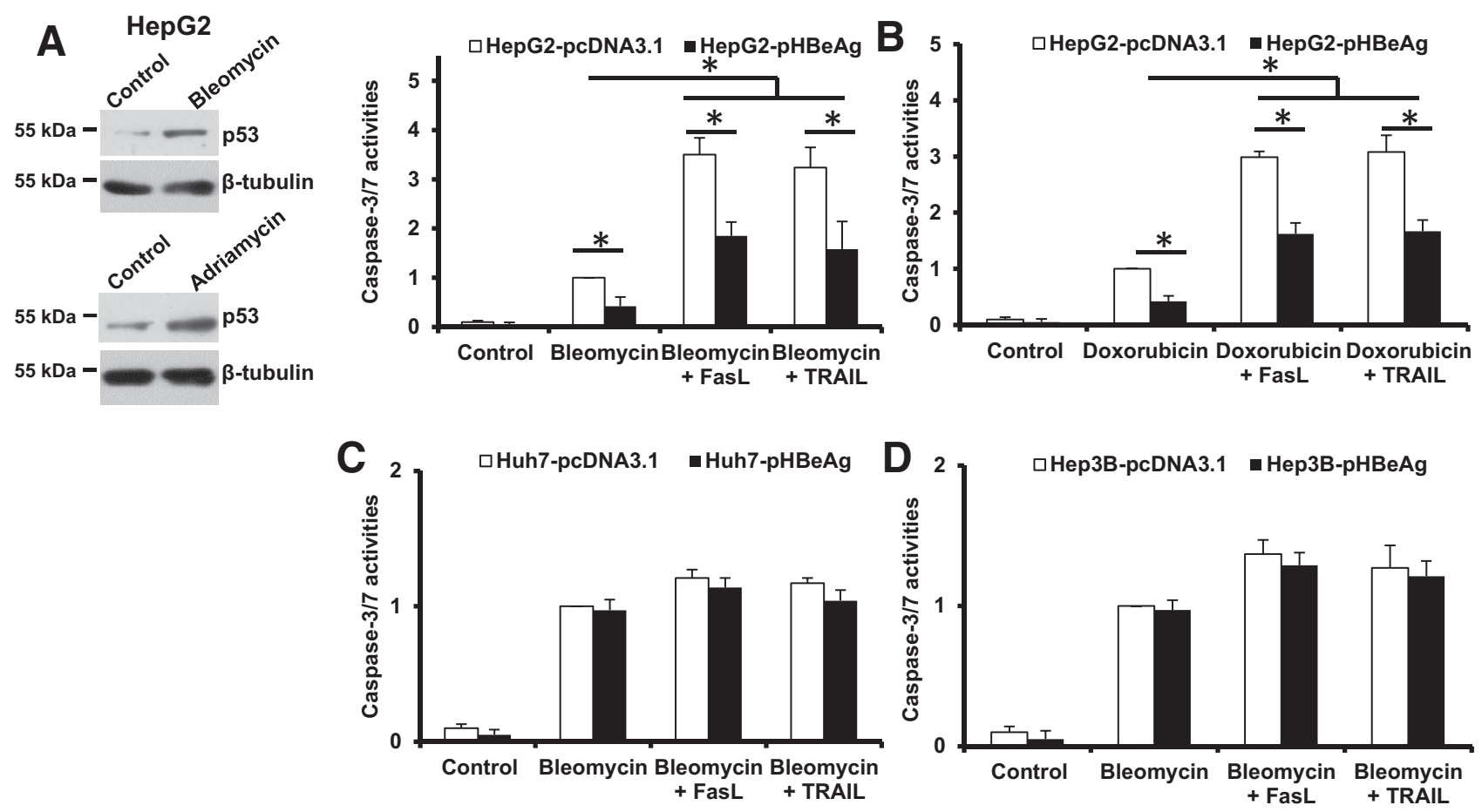
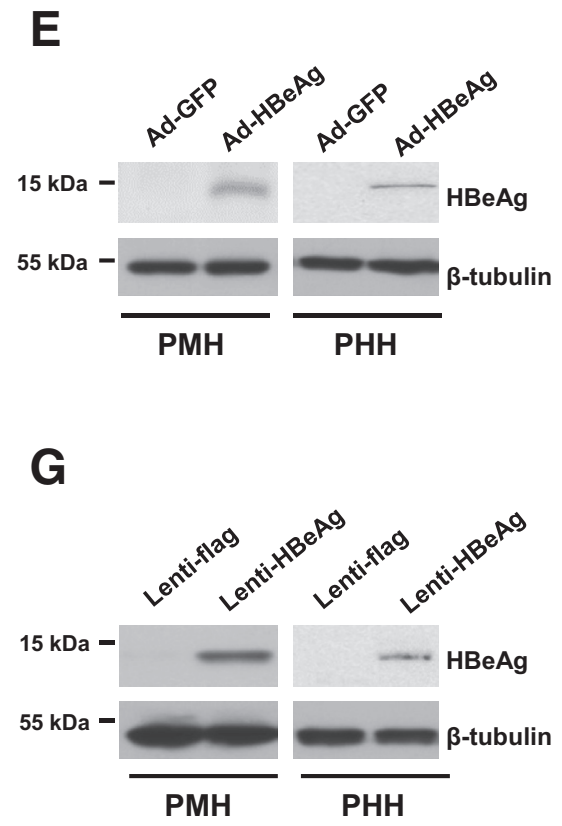
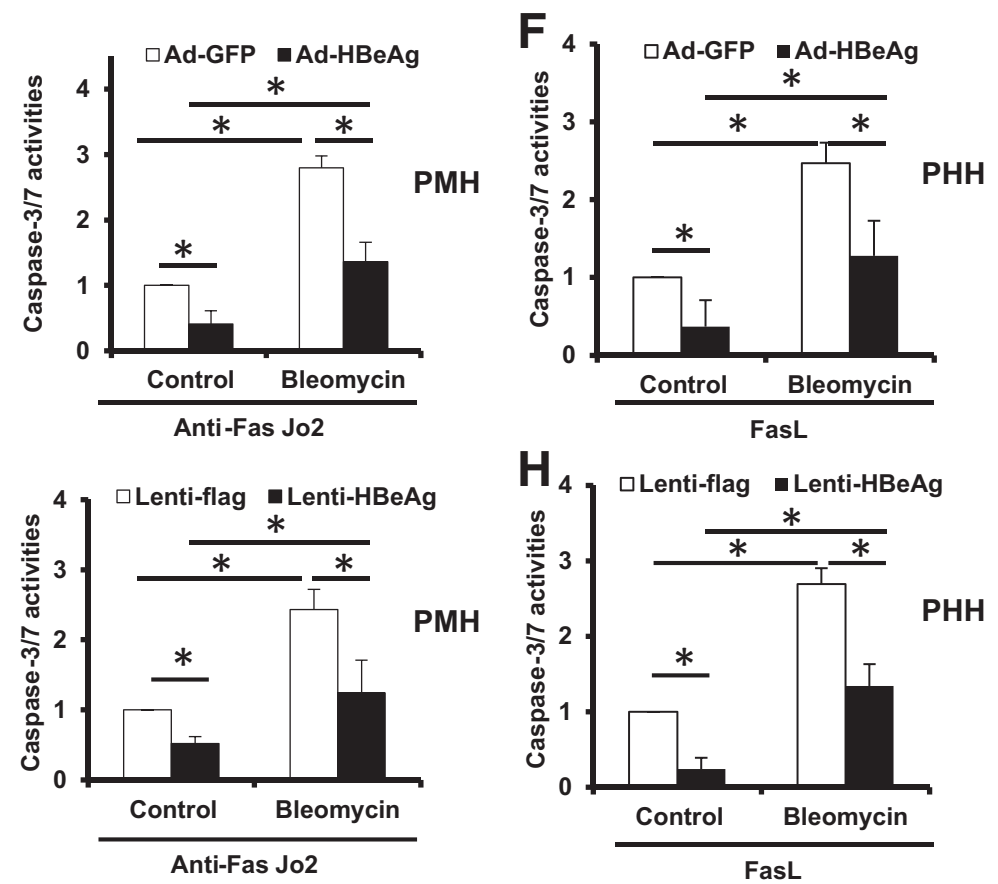

Figure 6 Hepatitis B virus (HBV) e antigen ( $\mathrm{HBeAg})$ increases resistance to death receptor-mediated apoptosis induced by DNA damaging agents. A-D: Measurements of caspase-3/7 enzymatic activity expressed as the fold change relative to that in the control cells at the indicated time points after treatment. E: Caspase-3/7 enzymatic activity of adenovirus (Ad) green fluorescent protein (GFP) or Ad-HBeAg-infected primary mouse hepatocytes (PMHs) after Jo2 stimulation. F: Caspase-3/7 enzymatic activity of Ad-GFP- or Ad-HBeAg-infected primary human hepatocytes (PHHs) after Fas ligand (FasL) stimulation. G: Caspase-3/7 enzymatic activity of Lenti-flag or Lenti-HBeAg-infected PMHs after Jo2 stimulation. H: Caspase-3/7 enzymatic activity of Lenti-flag- or Lenti$\mathrm{HBeAg}-$ infected PHHs after FasL stimulation. Data are expressed as means $\pm \mathrm{SD}(\mathbf{A}-\mathbf{H}) . n=3 .{ }^{*} P<0.05$ (analysis of variance).

hepatocytes. HBeAg inhibits the TRAIL apoptotic signal that is dependent on DR4 and DR5, which could be transcriptionally activated by $\mathrm{p} 53 .{ }^{16,17}$ The inhibitory effect of HBeAg on DR4 and DR5 expression was examined. $\mathrm{HBeAg}$ down-regulated the expression of DR4 and DR5 at both the mRNA and protein levels on p53 overexpression
(Figure 5, D and E). Lastly, HepG2-pHBeAg cells had a significant decrease of DR4 and DR5 promoter-driven luciferase reporter gene activity relative to HepG2pcDNA3.1 cells (Figure 5F). These data mainly illustrate that inhibition of TRAIL apoptotic signal by $\mathrm{HBeAg}$ is DR4 and DR5 dependent. 

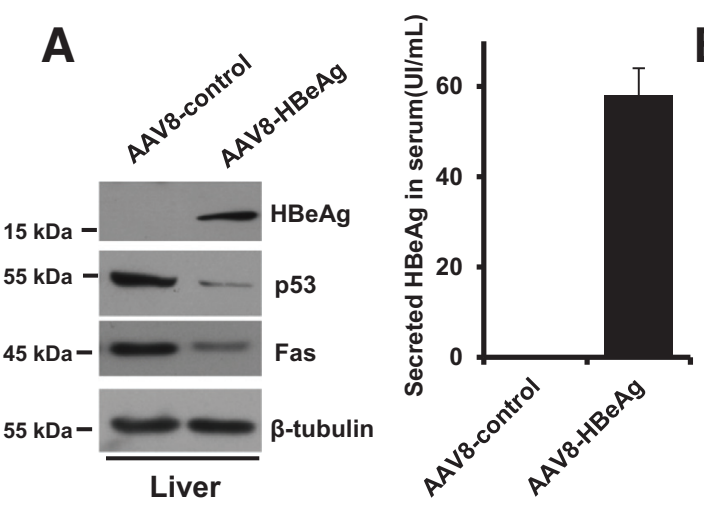

B

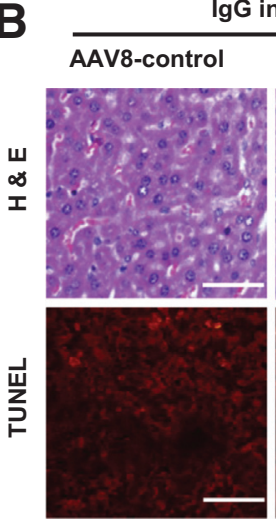

G injection
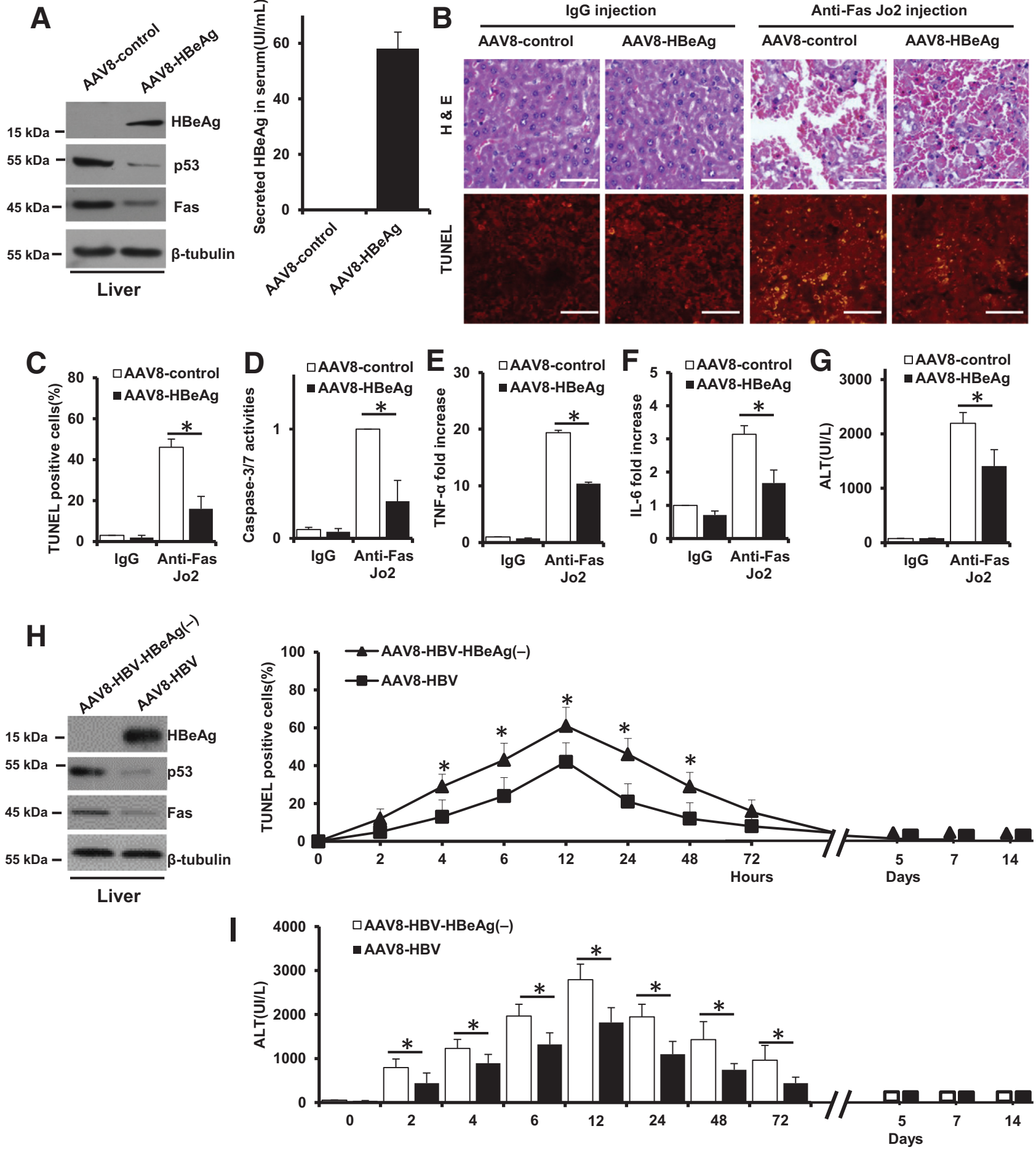

Figure 7 Hepatitis B virus (HBV) e antigen ( $\mathrm{HBeAg}$ ) protects $\mathrm{C} 57 \mathrm{BL} / 6$ mice from Fas-induced hepatic apoptosis. A: Protein extracts collected from the liver of adeno-associated virus (AAV)-8-HBeAg and control mice were resolved on SDS/PAGE and immunoblotted with indicated antibodies. Levels of serum HBeAg was tested quantitatively by Architect assay. The Architect HBeAg assay is calibrated to give results in international units per milliliter. B: Macroscopic appearance of representative liver samples with hematoxylin and eosin staining and terminal deoxynucleotidyl transferase-mediated dUTP nick-end labeling (TUNEL) staining 12 hours after Jo2 treatment of the different groups as indicated. C: The histogram summarizes the mean percentage of apoptotic cells in the livers of the indicated groups after Jo2 treatment. D: Caspase 8, 9, and 3/7 activity assay. Expression levels of tumor necrosis factor (TNF)- $\alpha$ (E) and IL-6 (F) and analyses of serum alanine aminotransferase (ALT) (G) showing that significantly less severity with regard to apoptosis, caspase activities, cytokine levels, and serum ALT levels is observed in AAV8-HBeAg mice. $\mathbf{H}$ and I: TUNEL and ALT assay shows that acute and severe cytolysis is observed in the AAV8-HBV-HBeAg(-) mice, whereas delayed and significantly less severe increase in intensity of apoptotic process are seen in AAV8-HBV mice. Return to normal values is observed within 5 days. Data are expressed as means \pm SD. $n=5$. ${ }^{*} P<0.05$ [analysis of variance (D-F) and $\chi^{2}$ test $(\mathbf{C}$ and $\left.\mathbf{G})\right]$. Scale bar $=100 \mu \mathrm{m}$. 

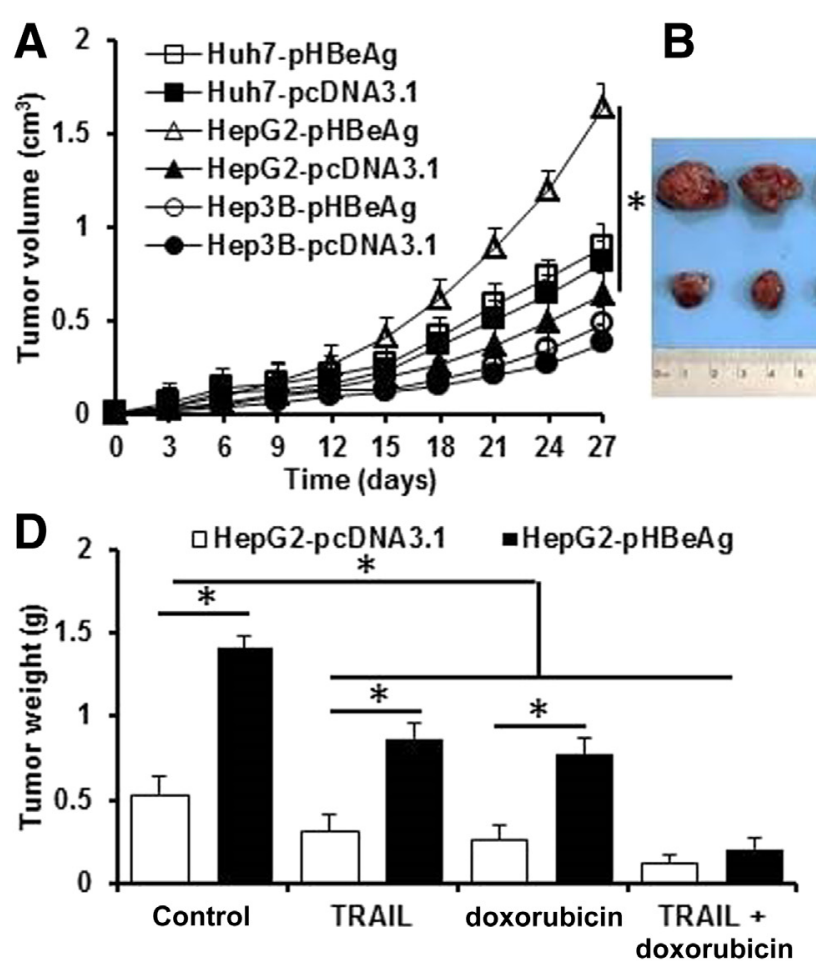

B

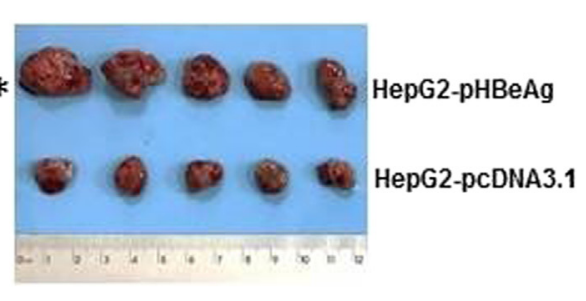

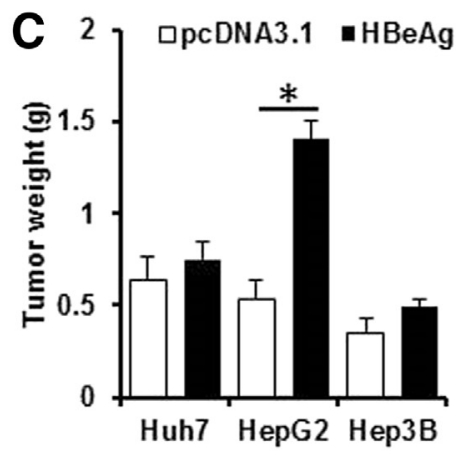

E

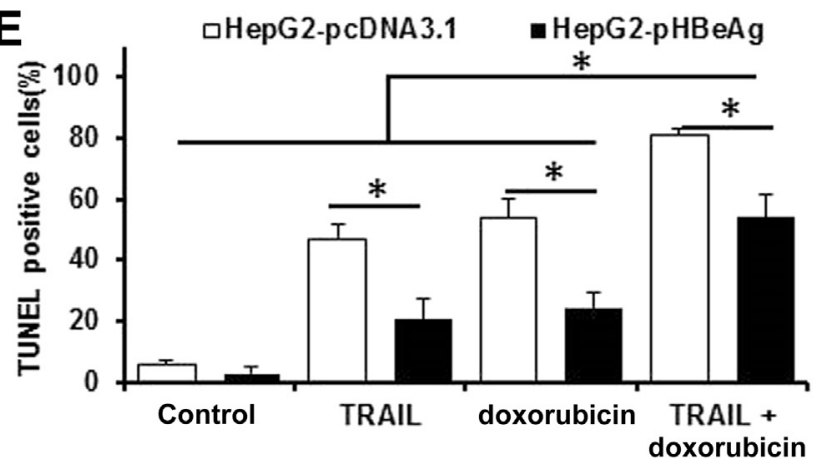

Figure 8 Hepatitis B virus (HBV) e antigen (HBeAg) inhibits the antitumor effect of tumor necrosis factor-related apoptosis-inducing ligand (TRAIL) in a human hepatoma xenograft model in vivo. A: In vivo subcutaneous tumor growth curves of HBeAg-expressing hepatoma cells and control cells. B: Images of all five harvested subcutaneous tumors from five nude mice of each group. C: Total tumor weight from each group of mice. D: Total tumor weight after TRAIL and/or doxorubicin treatment. E: The histogram summarizes the mean percentage of terminal deoxynucleotidyl transferase-mediated dUTP nick-end labeling (TUNEL) staining apoptotic cells in the subcutaneous tumors of the indicated groups after TRAIL and/or doxorubicin treatment. Data are expressed as means \pm SD. $n=5$. ${ }^{*} P<0.05\left[t\right.$-test $(\mathbf{A}$ and $\mathbf{C})$ analysis of variance $(\mathbf{D})$, and $\chi^{2}$ test $\left.(\mathbf{E})\right]$.

\section{HBeAg Increases Resistance to Death}

Receptor-Mediated Apoptosis Induced by DNA

\section{Damaging Agents}

One of the hallmarks of the cancer cell phenotype is chemotherapy resistance. ${ }^{33}$ It was therefore determined whether HBeAg could restrain the p53 apoptotic signal. To verify the correlation, two apoptosis inducers were used: bleomycin or doxorubicin, which induce p53-dependent apoptosis. $^{12}$ The results imply that the antiapoptotic effect of $\mathrm{HBeAg}$ was observed in bleomycin- or doxorubicin-pretreated and FasL- or TRAIL-mediated HepG2 (p53 wild-type) cells but not in Hep3B cells that express the deletion mutation of p53 or in Huh7 cells that harbors deficient mutant of p53 (Figure 6, A-D), further verifying that the antiapoptotic effect of $\mathrm{HBeAg}$ was $\mathrm{p} 53$ dependent. Because hepatoma cells may have abnormal death regulatory pathways, primary mouse or human hepatocytes were used to test whether HBeAg could also inhibit death receptor-mediated apoptosis triggered by anti-Fas Jo2 or FasL. Infection of PMHs or PHHs with an adenovirus or recombinant lentiviruses expressing $\mathrm{HBeAg}$ significantly suppressed Jo2-or FasL-induced apoptosis compared with the control virus-infected cells on bleomycin treatment (Figure 6, E-H). The data obviously illustrate that $\mathrm{HBeAg}$ can suppress the chemotherapy agent-induced and death receptor-mediated proapoptotic signaling pathway.

\section{HBeAg Prevents C57BL/6 Mice from Fas-Induced Hepatic Apoptosis}

To determine whether the effects of HBeAg on Fasmediated apoptosis in vitro could translate into responsiveness in vivo, anti-Fas Jo2 was injected intraperitoneally into mice to establish a Fas model. HBeAg, which had the highest ability of repressing p53 and mFas expression, was expressed in the livers of mice using a liver-targeted AAV8. Mice that successfully expressed $\mathrm{HBeAg}$ had decreased p53 and Fas expression (Figure 7A). No significant morphologic changes and histologic lesions were observed between the $\mathrm{HBeAg}$ and AAV8-control group, indicating that $\mathrm{HBeAg}$ alone did not affect liver histologic findings (Figure 7B). When Jo2 was injected intraperitoneally into the AAV8-control group, severe histologic lesions of the liver were observed in mice, including morphologic changes characteristic of apoptosis. In the control mice, early onset of massive apoptosis was observed 12 hours after the injection of Jo2 (Figure 7, B and C). The AAV8-HBeAg group had a significantly decreased hepatic apoptosis. Consistent with histologic data, a remarkable reduction of caspases-3/7 activities was detected in the liver extracts of 
AAV8-HBeAg group mice at 12 hours after Jo2 treatment (Figure 7D). Moreover, both reduced hepatic expression of inflammatory cytokines TNF- $\alpha$ and IL- 6 and decreased serum alanine aminotransferase were detected in AAV8$\mathrm{HBeAg}$ group mice compared with controls (Figure 7, E-G). In addition, AAV8-HBV mice with and without endogenous $\mathrm{HBeAg}$ expression were also used to verify the equivalent capacity of $\mathrm{HBeAg}$ in protecting Fas-mediated hepatocytes apoptosis from a nonlethal dose of Jo2 challenge (Figure 7, H and I). These results specifically indicate that $\mathrm{HBeAg}$ could prevent Fas-mediated hepatocyte cell death in vivo.

\section{HBeAg Inhibits the Antitumor Effect of TRAIL in a Human Hepatoma Xenograft Model in Vivo}

TNF- $\alpha$ and FasL can trigger apoptosis in solid tumors, but their clinical use has been limited by hepatotoxicity. TRAIL has a deep apoptotic effect on tumor cells but is nontoxic to human hepatocytes in vitro and in vivo. ${ }^{34}$ To elucidate the effect of $\mathrm{HBeAg}$ expression on tumor formation in vivo, tumor xenograft experiments were performed in nude mice with Huh7, HepG2, and Hep3B cells stably transfected with $\mathrm{HBeAg}$. Tumor xenograft experiments found that $\mathrm{HBeAg}$ stably expressing HepG2 cells had increased tumor growth compared with control cells as verified through tumor volume, photography, and weight measurement, and the phenotype was not observed in $\mathrm{HBeAg}$ stably expressing Huh7 cells or Hep3B cells (Figure 8, A-C), further verifying that the tumorigenicity of $\mathrm{HBeAg}$ was $\mathrm{p} 53$ dependent. The effects of HBeAg on TRAIL and/or chemotherapy agent-treated tumor tissues were then examined. Treatment of xenografted mice with TRAIL or doxorubicin caused stronger reduction of tumor weight in the control group than those of HBeAg stably expressing HepG2 cells (Figure 8D). The combination of TRAIL and doxorubicin was more effective than a single agent alone, which completely blocked the tumorigenicity of $\mathrm{HBeAg}$, and there was no obvious difference between HepG2-pHBeAg and control cells. At last, inhibition of the antitumor effect of TRAIL and/or chemotherapy agents by $\mathrm{HBeAg}$ in the xenograft model was verified by the TUNEL assay (Figure 8E). Collectively, $\mathrm{HBeAg}$ promoted p53-dependent tumor growth and inhibited the antitumor effect of TRAIL in a human hepatoma xenograft model.

\section{Discussion}

Hepatic apoptosis, primarily mediated by extrinsic proapoptotic factors such as FasL and TRAIL, promotes the occurrence and development of several liver diseases, including nonalcoholic steatohepatitis, viral hepatitis, and hepatocarcinogenesis. ${ }^{35}$ Verification of proapoptotic and antiapoptotic signal pathways relative to death receptor-mediated hepatic apoptosis would contribute significantly to understanding of the pathophysiologic role of apoptosis in the major liver diseases. Although death receptors are vital regulators of the proapoptotic pathway in hepatocytes and have been considered the key trigger of all types of liver diseases, ${ }^{36}$ the pivotal role for $\mathrm{HBeAg}$ in death receptor-mediated hepatic apoptosis has not been illustrated. The data suggest that HBV e protein is an effective survival factor capable of preventing hepatocytes from FasL and TRAIL-induced apoptosis through p53-dependent signaling pathway. Similaar to $\mathrm{HBc},{ }^{2} \mathrm{HBeAg}$ also serves as a Fas alternative splicing accelerator to up-regulate sFas transcription and expression, a known antagonist of Fas apoptotic signaling.

TRAIL may induce selective apoptosis of malignant and viral infected cells. Considering that the death receptor system plays a pivotal role in the pathogenic mechanism of HBV infection ${ }^{7,37}$ and in the development of inflammation, fibrosis, cirrhosis, and hepatocellular carcinoma, ${ }^{38} \mathrm{HBeAg}$ expression may lead to HBV chronic infection by reinforcing the resistance of infected hepatocytes to FasL- and TRAIL-induced apoptosis. In this study, HBeAg forcefully prevented hepatocytes from FasL- and TRAIL-evoked cytotoxicity. The finding that there was no differential cytotoxicity of FasL and TRAIL between $\mathrm{HBeAg}$ - and control-transfected Huh7 or Hep3B cells, both of which gain p53 dysfunction, indicates that p53 may be indispensable in $\mathrm{HBeAg}$-conferred apoptosis resistance, which was further verified in p53 wild-type HepG2 cells by p53 inhibition and p53 overexpression. Meanwhile, HBeAgsuppressing, chemotherapy agent-induced, and death receptor-mediated apoptosis was verified in primary human and mice hepatocytes. Furthermore, $\mathrm{HBeAg}$ prevented C57BL/6 mice from Fas-induced hepatic apoptosis and inhibited the antitumor effect of TRAIL in a human hepatoma xenograft model, which reflected the key role of $\mathrm{HBeAg}$ in apoptosis resistance and immunosuppression in vivo.

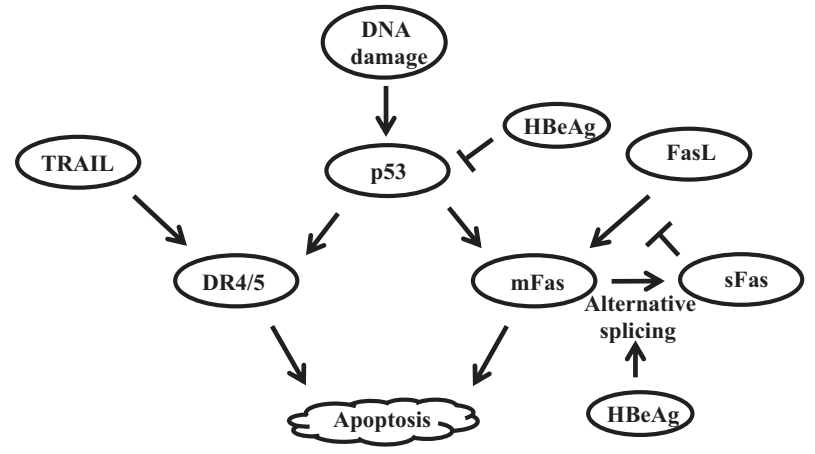

Figure 9 Schematic representation of hepatitis B virus (HBV) e antigen ( $\mathrm{HBeAg}$ ) regulation on $\mathrm{p} 53$ signaling to affect death receptor-apoptotic pathway. DR4, tumor necrosis factor receptor superfamily member 10a; DR5, tumor necrosis factor receptor superfamily member 10b; FasL, Fas ligand; mFas, membrane-associated Fas; sFas, soluble Fas; TRAIL, tumor necrosis factor-related apoptosis-inducing ligand. 
$\mathrm{HBeAg}$ is considered a nonstructural protein, although massive $\mathrm{HBeAg}$ is secreted to serum and $25 \%$ of the mature protein perhaps stays in the cytoplasm, ${ }^{21}$ which was verified by our experiment (Figures $1 \mathrm{~F}$ and $8 \mathrm{~A}$ ). Our research focuses on the multifunctions of the intracellular $\mathrm{HBeAg}$ and its precursors. $\mathrm{HBeAg}$ has been proposed to modulate the host immune response as a tolerogen to promote chronicity, which is a hallmark of HBV infection. Actually, HBV appears supervise the controlling of the immune response to strive for permanent and chronic infection. $\mathrm{HBeAg}$ or the HBV precore protein is an important viral protein hidden in HBV infection through the repression of the specific immune response. However, the mechanism for how $\mathrm{HBeAg}$ leads to hepatocarcinogenesis has not been illustrated. Recently, restrained p53 activity and the regulation of its downstream genes by $\mathrm{HBeAg} / \mathrm{HBV}$ have been reported in the $\mathrm{HBV}$-infected liver tumor tissues. ${ }^{21,39}$ In this work, it was illustrated that $\mathrm{HBeAg} /$ precore could downregulate p53-dependent mFas, DR4, and DR5 expression and exhibit strong resistance to apoptosis induced by FasL and TRAIL in vitro and in vivo, thereby enhancing carcinogenesis.

The clinical data point out that secreted $\mathrm{HBeAg}$ may play an immunoregulatory role in HBV infection. Conversely, intracellular $\mathrm{HBeAg}$ acts as a tolerogen for the specific immune response to promote chronicity, which is a hallmark of $\mathrm{HBV}$ infection. Besides inhibiting p53 expression, it has been illustrated that $\mathrm{HBeAg} /$ precore may repress NF- $\kappa \mathrm{B}$ signal and its downstream chemokines and inflammatory cytokines. ${ }^{40} \mathrm{HBeAg}$-deficient $\mathrm{HBV}$ variants have been described in both acute and chronic HBV infections. These variants harbor mutations in the precore region that inactivate the precore open reading frame, resulting in the deficiency of $\mathrm{HBeAg}$ expression. A stop codon mutation in codon 28 of the precore region occurs frequently. Chronic $\mathrm{HBV}$ infection has a heterogeneous clinical presentation and can be marked by fluctuations between wild-type virus and $\mathrm{HBeAg}$-negative variants that may predispose patients to a more aggressive form of disease. HBeAg-deficient HBV may cause more severe inflammation response compared with the wild type, and strong inflammation activity can worsen liver diseases with a possibility of slowly developing finally into hepatocellular carcinoma, which may partly explain why HBeAg-negative mutations can also lead to hepatocellular carcinoma in certain conditions. ${ }^{18,20} \mathrm{Un}$ like the core protein, $\mathrm{HBeAg}$ is not indispensable for viral replication because mutations that block its expression do not interfere with the HBV package. ${ }^{18,19}$ However, viruses defective in $\mathrm{HBeAg}$ production may contribute to a more severe course of acute hepatitis B. ${ }^{41,42}$ Therefore, HBeAg likely possesses negative immunomodulatory roles. ${ }^{43,44}$ The findings that inhibition of Fas and TRAIL apoptotic signal by $\mathrm{HBeAg}$ provide strong evidence for the above-mentioned views.

In summary, to our knowledge, these findings are the first to illustrate that $\mathrm{HBeAg}$ serves to inhibit p53-dependent
FasL- and TRAIL-mediated hepatic apoptosis by downregulating both $\mathrm{mFas}$ and $\mathrm{DR} 4 / 5$ expression at a transcriptional level and enhancing the expression of sFas by increasing Fas alternative splicing (Figure 9). The data indicate that $\mathrm{HBeAg}$ can protect hepatocytes from apoptosis induced by the Fas/FasL and TRAIL/DR system, thus leading to the survival of infected hepatocytes toward the development of HBV chronicity.

\section{Acknowledgments}

We thank Dr. Juan Valcárcel Juárez (Centre de Regulació Genòmica) for providing the pCMV56-Fas vector; and Dr. De-yin Guo (School of Basic Medical Sciences, Wuhan University, Wuhan, China) for providing the pcDNA3.1HBeAg, pcDNA3.1-precore, pcDNA3.1-p22, ad pcDNA3.1-p53.

T-F.G. and Z-T.J. designed and performed the experiments and analyzed data, with guidance from Q-Y.T. and W.L.; Z-T.J. provided expertise and contributed to the animal studies and the immunohistochemical staining of mouse tissues; W.L. conceptualized the project and wrote and edited the manuscript; all authors reviewed and approved the manuscript.

\section{References}

1. The Polaris Observatory Collaborators: Global prevalence, treatment, and prevention of hepatitis B virus infection in 2016: a modelling study. Lancet Gastroenterol Hepatol 2018, 3:383-403

2. Liu W, Lin YT, Yan XL, Ding YL, Wu YL, Chen WN, Lin X: Hepatitis B virus core protein inhibits Fas-mediated apoptosis of hepatoma cells via regulation of $\mathrm{mFas} / \mathrm{FasL}$ and $\mathrm{sFas}$ expression. FASEB J 2015, 29:1113-1123

3. Diao J, Khine AA, Sarangi F, Hsu E, Iorio C, Tibbles LA, Woodgett JR, Penninger J, Richardson CD: X protein of hepatitis B virus inhibits Fas-mediated apoptosis and is associated with upregulation of the SAPK/JNK pathway. J Biol Chem 2001, 276: $8328-8340$

4. Wu SX, Chen WN, Jing ZT, Liu W, Lin XJ, Lin X: Hepatitis B spliced protein (HBSP) suppresses Fas-mediated hepatocyte apoptosis via activation of PI3K/Akt signaling. J Virol 2018, 92. e01273-18

5. Guicciardi ME, Gores GJ: Apoptosis: a mechanism of acute and chronic liver injury. Gut 2005, 54:1024-1033

6. Guicciardi ME, Gores GJ: Life and death by death receptors. FASEB J 2009, 23:1625-1637

7. Galle PR, Hofmann WJ, Walczak H, Schaller H, Otto G, Stremmel W, Krammer PH, Runkel L: Involvement of the CD95 (APO-1/Fas) receptor and ligand in liver damage. J Exp Med 1995, 182:1223-1230

8. Cascino I, Fiucci G, Papoff G, Ruberti G: Three functional soluble forms of the human apoptosis-inducing Fas molecule are produced by alternative splicing. J Immunol 1995, 154:2706-2713

9. Rivero M, Crespo J, Fabrega E, Casafont F, Mayorga M, GomezFleitas M, Pons-Romero F: Apoptosis mediated by the Fas system in the fulminant hepatitis by hepatitis B virus. J Viral Hepat 2002, 9: 107-113

10. Jodo S, Kobayashi S, Nakajima Y, Matsunaga T, Nakayama N, Ogura N, Kayagaki N, Okumura K, Koike T: Elevated serum levels of soluble Fas/APO-1 (CD95) in patients with hepatocellular carcinoma. Clin Exp Immunol 1998, 112:166-171 
11. Müller M, Strand S, Hug H, Heinemann E-M, Walczak H, Hofmann WJ, Stremmel W, Krammer PH, Galle PR: Drug-induced apoptosis in hepatoma cells is mediated by the CD95 (APO-1/Fas) receptor/ligand system and involves activation of wild-type p53. J Clin Invest 1997, 99:403

12. Müller M, Wilder S, Bannasch D, Israeli D, Lehlbach $\mathrm{K}$, LiWeber M, Friedman SL, Galle PR, Stremmel W, Oren M: p53 activates the CD95 (APO-1/Fas) gene in response to DNA damage by anticancer drugs. J Exp Med 1998, 188:2033-2045

13. Fridman JS, Lowe SW: Control of apoptosis by p53. Oncogene 2003, 22:9030-9040

14. Jia B, Guo M, Li G, Yu D, Zhang X, Lan K, Deng Q: Hepatitis B virus core protein sensitizes hepatocytes to tumor necrosis factorinduced apoptosis by suppression of the phosphorylation of mitogen-activated protein kinase kinase 7. J Virol 2015, 89: 2041-2051

15. Huang Q, Wang L, Bai S, Lin W, Chen W, Lin J, Lin X: Global proteome analysis of hepatitis B virus expressing human hepatoblastoma cell line HepG2. J Med Virol 2009, 81:1539-1550

16. Liu X, Yue P, Khuri FR, Sun SY: p53 upregulates death receptor 4 expression through an intronic p53 binding site. Cancer Res 2004, 64: 5078-5083

17. Takimoto R, El-Deiry WS: Wild-type p53 transactivates the KILLER/DR5 gene through an intronic sequence-specific DNA-binding site. Oncogene 2000, 19:1735-1743

18. Milich D, Liang TJ: Exploring the biological basis of hepatitis B e antigen in hepatitis B virus infection. Hepatology 2003, 38: $1075-1086$

19. Walsh R, Locarnini S: Hepatitis B precore protein: pathogenic potential and therapeutic promise. Yonsei Med J 2012, 53:875-885

20. Tsai KN, Kuo CF, Ou JJ: Mechanisms of hepatitis B virus persistence. Trends Microbiol 2018, 26:33-42

21. Liu D, Cui L, Wang Y, Yang G, He J, Hao R, Fan C, Qu M, Liu Z, Wang M, Chen L, Li H, Guo D: Hepatitis B e antigen and its precursors promote the progress of hepatocellular carcinoma by interacting with NUMB and decreasing p53 activity. Hepatology 2016, 64:390-404

22. Liu W, Jing ZT, Wu SX, He Y, Lin YT, Chen WN, Lin XJ, Lin X: A novel AKT activator, SC79, prevents acute hepatic failure induced by Fas-mediated apoptosis of hepatocytes. Am J Pathol 2018, 188: $1171-1182$

23. Lin YJ, Huang LR, Yang HC, Tzeng HT, Hsu PN, Wu HL, Chen PJ, Chen DS: Hepatitis B virus core antigen determines viral persistence in a C57BL/6 mouse model. Proc Natl Acad Sci U S A 2010, 107: 9340-9345

24. Wu YL, Wang D, Peng XE, Chen YL, Zheng DL, Chen WN, Lin X: Epigenetic silencing of $\mathrm{NAD}(\mathrm{P}) \mathrm{H}$ :quinone oxidoreductase 1 by hepatitis B virus $\mathrm{X}$ protein increases mitochondrial injury and cellular susceptibility to oxidative stress in hepatoma cells. Free Radic Biol Med 2013, 65:632-644

25. Liu W, Guo TF, Jing ZT, Yang Z, Liu L, Yang YP, Lin X, Tong QY: Hepatitis B virus core protein promotes hepatocarcinogenesis by enhancing Src expression and activating the Src/PI3K/Akt pathway. FASEB J 2018, 32:3033-3046

26. Jing ZT, Liu W, Wu SX, He Y, Lin YT, Chen WN, Lin XJ, Lin X: Hepatitis B virus surface antigen enhances the sensitivity of hepatocytes to Fas-mediated apoptosis via suppression of AKT phosphorylation. J Immunol 2018, 201:2303-2314

27. Jing ZT, Liu W, Xue CR, Wu SX, Chen WN, Lin XJ, Lin X: AKT activator SC79 protects hepatocytes from TNF-alpha-mediated apoptosis and alleviates d-Gal/LPS-induced liver injury. Am J Physiol Gastrointest Liver Physiol 2019, 316:G387-G396

28. Du J, Liang X, Liu Y, Qu Z, Gao L, Han L, Liu S, Cui M, Shi Y, Zhang Z, Yu L, Cao L, Ma C, Zhang L, Chen Y, Sun W: Hepatitis B virus core protein inhibits TRAIL-induced apoptosis of hepatocytes by blocking DR5 expression. Cell Death Differ 2009, 16:219-229

29. Fukazawa T, Fujiwara T, Morimoto Y, Shao J, Nishizaki M, Kadowaki Y, Hizuta A, Owen-Schaub LB, Roth JA, Tanaka N: Differential involvement of the CD95 (Fas/APO-1) receptor/ligand system on apoptosis induced by the wild-type p53 gene transfer in human cancer cells. Oncogene 1999, 18:2189-2199

30. Hsu IC, Tokiwa T, Bennett W, Metcalf RA, Welsh JA, Sun T, Harris CC: p53 gene mutation and integrated hepatitis B viral DNA sequences in human liver cancer cell lines. Carcinogenesis 1993, 14: 987-992

31. Ponchel F, Puisieux A, Tabone E, Michot JP, Froschl G, Morel AP, Frebourg T, Fontaniere B, Oberhammer F, Ozturk M: Hepatocarcinoma-specific mutant p53-249ser induces mitotic activity but has no effect on transforming growth factor beta 1-mediated apoptosis. Cancer Res 1994, 54:2064-2068

32. Cheng J, Zhou T, Liu C, Shapiro JP, Brauer MJ, Kiefer MC, Barr PJ, Mountz JD: Protection from Fas-mediated apoptosis by a soluble form of the Fas molecule. Science 1994, 263:1759-1762

33. Hanahan D, Weinberg RA: Hallmarks of cancer: the next generation. Cell 2011, 144:646-674

34. Hao C, Song JH, Hsi B, Lewis J, Song DK, Petruk KC, Tyrrell DL, Kneteman NM: TRAIL inhibits tumor growth but is nontoxic to human hepatocytes in chimeric mice. Cancer Res 2004, 64: $8502-8506$

35. Luedde T, Kaplowitz N, Schwabe RF: Cell death and cell death responses in liver disease: mechanisms and clinical relevance. Gastroenterology 2014, 147:765-783.e4

36. Akazawa Y, Gores GJ: Death receptor-mediated liver injury. Semin Liver Dis 2007, 27:327-338

37. French LE, Tschopp J: The TRAIL to selective tumor death. Nat Med 1999, 5:146-147

38. Nakamoto Y, Guidotti LG, Pasquetto V, Schreiber RD, Chisari FV: Differential target cell sensitivity to CTL-activated death pathways in hepatitis B virus transgenic mice. J Immunol 1997, 158:5692-5697

39. Liu N, Liu Q, Yang X, Zhang F, Li X, Ma Y, Guan F, Zhao X, Li Z, Zhang L, Ye X: Hepatitis B virus-upregulated lnc-HUR1 promotes cell proliferation and tumorigenesis by blocking p53 activity. Hepatology 2018, 68:2130-2144

40. Lang T, Lo C, Skinner N, Locarnini S, Visvanathan K, Mansell A: The hepatitis $\mathrm{B}$ e antigen ( $\mathrm{HBe} \mathrm{Ag}$ ) targets and suppresses activation of the toll-like receptor signaling pathway. J Hepatol 2011, 55: 762-769

41. Mina T, Amini Bavil Olyaee S, Tacke F, Maes P, Van Ranst M, Pourkarim MR: Genomic diversity of hepatitis B virus infection associated with fulminant hepatitis B development. Hepat Mon 2015, 15:e29477

42. Petrosillo N, Ippolito G, Solforosi L, Varaldo PE, Clementi M, Manzin A: Molecular epidemiology of an outbreak of fulminant hepatitis B. J Clin Microbiol 2000, 38:2975-2981

43. Chen MT, Billaud JN, Sallberg M, Guidotti LG, Chisari FV, Jones J, Hughes J, Milich DR: A function of the hepatitis B virus precore protein is to regulate the immune response to the core antigen. Proc Natl Acad Sci U S A 2004, 101:14913-14918

44. Guidotti LG, Isogawa M, Chisari FV: Host-virus interactions in hepatitis B virus infection. Curr Opin Immunol 2015, 36:61-66 